TI 2017-118/VI

Tinbergen Institute Discussion Paper
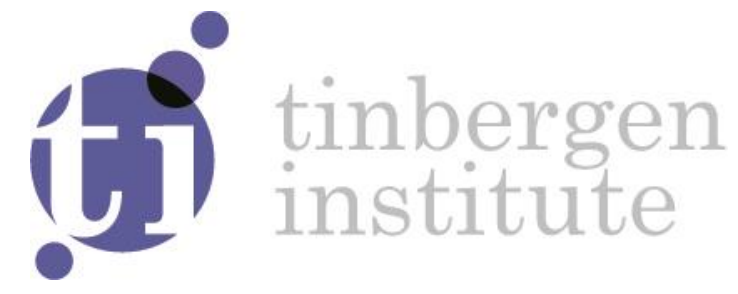

Between spilling over and boiling down: network-mediated spillovers, absorptive capacity and productivity in European regions

Nicola Cortinovis ${ }^{1}$

Frank van Oort ${ }^{2}$

\footnotetext{
${ }^{1}$ Erasmus University Rotterdam

${ }^{2}$ ESE EUR, IHS Eur, Utrecht University
} 
Tinbergen Institute is the graduate school and research institute in economics of Erasmus University Rotterdam, the University of Amsterdam and VU University Amsterdam.

Contact: discussionpapers@tinbergen.nl

More TI discussion papers can be downloaded at http://www.tinbergen.nl

Tinbergen Institute has two locations:

Tinbergen Institute Amsterdam

Gustav Mahlerplein 117

1082 MS Amsterdam

The Netherlands

Tel.: +31(0)205984580

Tinbergen Institute Rotterdam

Burg. Oudlaan 50

3062 PA Rotterdam

The Netherlands

Tel.: +31(0)10408 8900 


\title{
Between spilling over and boiling down: network-mediated spillovers, absorptive capacity and productivity in European regions
}

\author{
Nicola Cortinovis \\ Frank van Oort
}

\begin{abstract}
Productivity across European regions is related to three types of networks that mediate R\&D-related knowledge spillovers: trade, co-patenting and geographical proximity. Both our panel and instrumental variable estimations for European regions suggest that network relations are crucial sources of $R \& D$ spillovers, but with potentially different features. While co-patenting relations appear to affect local productivity directly, regions that link up to innovative leader regions via imports gain in productivity only when they have relatively high levels of human capital and absorptive capacity. From a policy perspective, this may frustrate recent European policy initiatives, such as Smart Specialization, that are designed to benefit all regions in Europe.
\end{abstract}

\section{Introduction}

Linkages between different peoples and countries, through trade, capital and cultural ties, have had large economic effects since the beginning of human civilization. Over the past few decades, the opportunities for exchanging goods, services, technologies and knowledge have dramatically increased, bringing the concepts of networks, interaction, and diffusion to the forefront of academic and political debates. Economics and economic geography have increasingly focused on the role of spatial and network relations and relate it to innovation and productivity performance.

Departing from the crucial role of knowledge in fostering innovation, productivity and development (Romer 1986, Lucas 1988), different scholars have investigated how spatial and network relations mediate and allow for the diffusion of ideas and technologies across space (Jones 1995, Durlauf et al. 2001). Early contributions (Jaffe et al. 1993, Jaffe and Trajtenberg 1999, Grossman and Helpman, 1991, Coe and Helpman 1995) have focused on local spillover effects of patents and trade relations 
as channels for knowledge exchange. More recently, these contributions have been extended by a number of scholars looking at spatial, market, investment and technological relations as sources of productivity and innovation both at country level (Keller 2002, Lumenga-Neso et al. 2005, Fracasso and Vitucci Marzetti 2015) and firm level (Keller and Yeaple 2009, Bloom et al. 2013, Lychagin et al. 2016). While studies at country and firm level focus on specific channels, economists have provided less detailed evidence at regional level, with most of the literature merely referring to spatial spillovers (Bottazzi and Peri, 2002, Le Gallo and Dall'Erba 2008).

Building on older contributions of industrial districts (Becattini et al. 2009), economic geography literature focused more closely on the regional effects of space and networks. Putting as theoretical cornerstones the concepts of proximity and relatedness, this stream of research investigates and, with varying success, empirically tests, what types of relatedness mold knowledge interaction, learning and innovation (Torre et al. 1999, Boschma 2005, Ratti et al. 1997, Camagni 1991, Frenken et al. 2007). Whereas traditionally more interested in the role of local factors and conditions, the proximity-based literature has increasingly investigated the role of wider spatial relations and networks. Different contributions have considered the effects of spatial spillovers, co-patenting, industrial and technological similarity, and migration as channels for the diffusion of knowledge (Maggioni et al 2007; Caragliu and Nijkamp 2015, Paci et al. 2014, Miguelez and Moreno 2015). Apart from coinventorship relations, these contributions (with the exception of Thissen et al. 2016) have paid less attention to the traditional factors - such as trade and investments identified by growth literature.

This paper wants to link these two successful streams of literature by investigating the productivity effects of spatial and network relations at regional level. More specifically, this paper is among the first to directly study the impact of import, copatenting and spatial relations vis-à-vis each other. Besides, given the unequal distribution of knowledge assets and innovating capabilities across regions, it can be expected that not all linkages are equally important for each and every region (Hoekman et al. 2009) and conditions for profiting from network relations may exist 
(Miguelez and Moreno 2015). Based on these intuitions, we test whether linkages to most advanced regions provide a significant benefit for recipient ${ }^{1}$ regions

The aim of this paper is three-fold. Firstly, we investigate in a spatial panel setting with region and year fixed effects whether and how network relations affect local productivity, once the spatial proximity dimension is controlled for. Secondly, we specifically model network relations with most knowledge and technologically advanced regions (Wintijes and Hollanders 2010, Cortinovis and Van Oort 2015) to study whether such linkages provide directed spillover effects. Thirdly, we test whether the stock of absorptive capabilities of regions (on an educational level) act as precondition for regions to profit (take in) from network relations with most advanced regions (Miguelez and Moreno 2015, Cortinovis and Van Oort 2015). Finally, we check the validity of our potentially endogenous results with an instrumental variable (IV) strategy, in which illiteracy rates and gross reproduction rates in European regions in the early 1930s are used as an instrument for current $R \& D$ expenditures.

Our empirical analysis put forward a number of important results. First, both our spatial panel and IV estimates highlight that, even controlling for spatial effects in $\mathrm{R} \& \mathrm{D}$ spillovers and in the residuals, network relations affect regional productivity. In particular, cross-regional cooperation on patents is an important vector of technological diffusion, resulting in higher levels of productivity for regions. Similarly, trade relations (measured by import flows in intermediate goods) also have a direct effect on productivity, but only in the case of more technologically advanced imports. Second, whereas the effects of co-patenting-mediated R\&D spillovers are not found to depend on local human capital, trade relations with most knowledgeendowed regions provide productivity advantages to recipient regions only when conditions of absorptive capacity (including human capital) are met. At least with respect to trade relations, without interregional network linkages and strong absorptive capacity, spillovers do not occur. Instead, productivity advantages will boil down in only the most advanced and well-connected regions. This questions policy efforts to link catching-up European regions in terms of productivity (with currently

\footnotetext{
${ }^{1}$ In the paper, we use the terms "linking-in", "connecting" and "recipient" regions as synonyms. These refer to regions which are "in touch", either via import or via co-patenting, with most innovative regions. These terms do not attribute any characteristic to the regions. For instance, a "recipient region" can be either a lagging region, an innovative follower or an innovation leader.
} 
low starting values in Eastern Europe and low growth rates in Southern Europe) by the introduction of a European Research Area (Frenken et al. 2007) and smart specialization strategies (Foray 2015).

To reach these conclusions, we structure our paper as follows. The theoretical underpinnings of spatial and network spillovers are discussed and related to absorptive capacity and knowledge capabilities in advanced regions in the second section of the paper. Based on the theoretical discussion, we pose two research questions and three testable hypotheses, followed, in the third section of the paper, by a discussion on the models, methods and data sources used in the empirical analysis. The results of our econometric exercises are reviewed and interpreted in the fourth section. The final part is devoted to the discussion of policy and research implications related to our findings.

\section{Theoretical framework: knowledge spillovers, absorptive capacity and}

\section{linkages to advanced regions}

\section{Localized knowledge and spatial spillovers}

The idea of spillovers has been widely studied by economists and geographers, especially in relation to agglomeration economies and knowledge flows across space. Agglomeration economies literature usually distinguishes between intra-sectoral and inter-sectoral spillovers, depending on whether the beneficial effects of agglomerations arise and are captured within the same industry or in the broader economic environment (Marshall 1920, Jacobs 1969, Glaeser et al. 1992, Beaudry and Shiffauerova 2009). Regardless of whether they come from a firm in the same sector or emerge from knowledge recombination in a diversified urban environment, these spillovers are considered as inherently localized, not spanning further than what faceto-face interactions allow (Breschi and Lissoni 2001). Precisely because of their localized nature, knowledge externalities are used to explain the emergence and persistence of spatial disparities in development and economic performance (Capello 2009, Lissoni and Miguelez 2014). 
It is thus not surprising that the spatial dimension of knowledge spillovers has received significant attention in economic geography and regional studies. Especially since the development of spatial econometric tools, different studies have shown that knowledge exchanges occur across the borders of cities, clusters and regions, even though they are facilitated by geographical proximity and subject to distance decay (Dall'Erba and Le Gallo 2008, Arbia et al. 2010, Caragliu and Nijkamp 2015, Lissoni and Miguelez 2014). Empirical research has provided significant evidence in these respects, even estimating the range within which spillovers can be expected. Bottazzi and Peri (2002) show that within Europe, knowledge externalities have a significant impact within a range of $200-300 \mathrm{~km}$, dying out once this distance threshold is crossed. Similarly, Crescenzi and Rodriguez-Pose (2011) find evidence of knowledge exchange within a range of a three-hour drive but not further than that. Works by Greunz (2003) and Moreno et al. (2005) find significant effects of knowledge spillover within comparable distance ranges.

Whereas significant evidence has been produced empirically on the existence of spatial spillovers, these effects are conceptually justified by reference to the lower costs and the greater probability of meeting and having face-to-face interactions. This interpretation has however been criticized, in particular considering that geographical proximity without any other network infrastructure linking two individuals or firms does not lead to knowledge diffusion (Boschma 2005, Torre and Rallet 2005, Capello 2009).

\section{Network-mediated knowledge spillovers}

The idea of socio-economic linkages as infrastructure that allows knowledge diffusion within localities, across space, among specific actors or in the broader community is not new (Granovetter 1973, Conly et al. 2002, Akerlof 1997, Camagni, 1991, Morrison and Rabelotti 2009, Bathelt et al. 2004). Boschma (2005) offers a general critique of the role of spatial proximity as the major catalyst for knowledge spillovers, suggesting that along with spatial closeness, other forms of networked proximity may facilitate knowledge spillovers. In this sense, connections with cognitively similar actors, even if located far away, can provide access to valuable information for firms and individuals (Nooteboom 1992, Frenken et al. 2007). Building on endogenous growth and evolutionary arguments, Huggins et al. (2012) and Huggins and 
Thompson (2014) have developed the concept of "network capital" which theorize a tight conceptual link between local economic performance and the ability to access economically valuable knowledge through network linkages.

In this sense, while geographical distance makes it costlier and harder to diffuse ideas and technologies, network relations still make such exchanges possible. In these respects, the literature has theoretically discussed and empirically investigated whether and how different linkages enable knowledge to diffuse ${ }^{2}$.

The mechanisms linking international trade, innovation and growth have been studied in a long tradition (Fagerberg 1988, Romer 1986). While technological and knowledge transfers are not automatic in trade relations, international economists have realized how trade connections can give access to relevant cognitive resources (Grossman and Helpman 1994). Coe and Helpman (1995) provide theoretical arguments establishing the link between international trade and R\&D spillovers. Based on the idea that most international trade is in intermediate goods, the importing economy can increase its production thanks to the technological progress and innovation from trading partners. In this sense, the effects of using more technologically advanced imported inputs is complemented by the possibility for the importing firms to learn about new technologies, process, materials and organizational practices. Empirical evidence on these mechanisms has confirmed the beneficial effects of import-mediated foreign $R \& D$ across countries (Coe and Helpman 1995, Coe et al. 2009, Fracasso and Vitucci Marzetti 2015) as expenditures in R\&D by trading partners contribute to local productivity in the importing country. At firm level, however, the impact of import-mediated R\&D appears to be weaker (Keller and Yeaple 2009). Finally, in a regional perspective, Thissen et al. (2016) have recently demonstrated the relevance of trade networks for European regions, showing that trade relations can explain sectoral growth in productivity across EU regions.

\footnotetext{
${ }^{2}$ In addition to trade and various forms of proximity, different studies have highlighted how investment flows (Iammarino and McCann 2013, Keller and Yeaple 2009), migration networks (Lissoni 2016, Hornung, 2010) and global value chains (Giuliani 2005, Morrison et al. 2008) work as channels for knowledge diffusion. For sake of brevity, we do not discuss these in this paper.
} 
Following Boschma (2005), different empirical studies have investigated the role of different forms of proximity in the diffusion of knowledge concluding that, while geographical closeness facilitates the acquisition of new knowledge, other forms of proximity seem to act as conditioning factors (Caragliu and Nijkamp 2015, Paci et al. 2014, Morrison and Rabellotti 2009). In these studies, co-patenting and collaborative relations among inventors - used as a proxy for relational closeness - are of large hypothesized importance (Maggioni et al. 2007, Maggioni and Uberti 2009; Miguelez and Moreno 2015). The conceptual link between co-patenting networks and knowledge spillovers is rather straightforward: co-patenting is a process that involves a substantial and successful exchange of knowledge between individuals, which leads to the acquisition of a patent. By taking part in processes of collective learning based on knowledge sharing, local actors have the opportunity to acquire fresh knowledge that has originated elsewhere and bring it to the local context. While this has a direct effect on the local performance through innovation and eventually growth (Caragliu and Nijkamp 2015), the effects of collaborative relations have mostly been assessed with respect to local innovation performance only (Maggioni et al. 2007, Ponds et al. 2010, Hoekman et al. 2009, Paci et al. 2014). A notable exception is Basile et al. (2012), whose paper reach similar conclusions, demonstrating the synergic effects between spatial and relational/social proximities on productivity growth.

From this short discussion of the literature on spillovers, three main channels for the transmission of knowledge surface. The literature on agglomeration economies strongly focuses on the spatial dimension of knowledge spillovers, stressing their localized nature (Lissoni and Miguelez 2014, Bottazzi and Peri 2002, Keller 2002). Similarly, studies on growth and international trade suggest that through imports, local actors can acquire and capitalize on knowledge that has originated elsewhere (Coe and Helpman 1995, Lumenga-Neso et al. 2005, Keller and Yeaple 2009). Finally, scientists in the field of geography of innovation claim co-inventorship and co-patenting relations, as a form of relational proximity (Boschma 2005), affect local economic performance (Basile et al. 2012). Supportive, but sometimes suggestive, empirical evidence has been produced for each of these channels individually. However, only a few attempts have been made to analyze these contributions simultaneously or vis-à-vis one another. As the influence of space and network affect 
the regional economy concurrently, we formulate the first research question that we will address in this paper:

RQ 1: Once spatial proximity is controlled for, do networked trade and networked copatenting relations affect regional productivity, and is any of these two channels more relevant than the other?

\section{Origin of knowledge and absorptive capacity of the recipient}

While significant attention has been devoted to understanding whether knowledge externalities really exist, less attention has been paid to the characteristics of the parties involved in the knowledge exchange and especially to the features of organization or the place from which the knowledge originates. Most country-level studies (Grossman and Helpman 1990, Coe and Helpman 1995, Coe et al. 2009) and regional studies (Caragliu and Nijkamp 2015, Basile et al. 2012, Paci et al. 2014, Greunz 2003) assume that regardless of whether knowledge spillovers originate from a highly advanced economy or a more backwashed one, the inflow of knowledge outside-in will be equally beneficial. A relevant exception in this case is Mancusi (2008), who looks at patents and patent citations and finds that technologically leading countries act as spillovers sources rather than recipients.

Conceptually, the issue of the source of knowledge spillovers is partially addressed by the idea of network capital (Huggins et al. 2012, Huggins and Thompson 2014). With their network capital, regions acquire the ability to "access and subsequently utilize appropriate economically beneficial knowledge" (Huggings and Thompson, 2014, p. 532). The relation between economically valuable knowledge, network and local performance thus suggest that linkages to most advanced economies, which embody most valuable knowledge, should provide access to potentially groundbreaking knowhow. The international business literature has also reached similar conclusions, showing that spillovers to domestic firms are influenced by factors on the "input" side, such as the origin of the multinational, the type of industry, and the mode and reason for entry (Crespo and Fontoura 2007, Fu et al. 2011).

Unlike the issue of the source of knowledge, different contributions have shown that some preconditions are necessary for a recipient (firm, country or region) to benefit 
from knowledge externalities (Abreu et al. 2004). As for firm absorptive capacity, which depends on the amount of prior related knowledge that the firm has (Cohen and Levinthal, 1990, Knoben et al. 2016), regions and countries may face preconditions for translating knowledge spillovers into innovation and growth (Benhabib and Spiegel 2005, Nelson and Phelps 2006, Caragliu and Nijkamp, 2008). While this has been shown to be the case for agglomeration externalities within the boundaries of the local economy (Cortinovis and Van Oort, 2015), similar arguments hold for crossborder spillovers and knowledge exchanges (Caragliu and Nijkamp 2008, Beugelsdijk et al. 2008, Miguelez and Moreno 2015).

Based on the discussion of the sources of knowledge and recipient's absorptive capacity, we theorize that different regions produce knowledge spillovers of different qualities according to their level of technological progress. Connections to most advanced places may then provide access to particularly valuable spillovers, generated from state of art knowledge. At the same time, as advanced knowledge tends to be particularly complex and requires specific skills and competences (Balland and Rigby 2015, Miguelez and Moreno 2015), greater absorptive capacity may be needed for regions to fruitfully assimilate those spillovers. On these bases, we put forward our second research question:

RQ 2: Do relations to most advanced regions provide a particular advantage for inlinking regions for regional productivity, and are absorptive capacities necessary to substantiate these benefits?

\section{$\underline{\text { Research hypotheses }}$}

The relationship between knowledge spillovers, either mediated by space or networks, and economic performance has been studied in different streams of economic research. In spite of recent exceptions (Bloom et al. 2013, Lychagin et al. 2016), studies in the growth and cross-border R\&D spillover literature tend to ignore the subnational territorial dimension and almost exclusively focus on spillovers mediated by trade (Coe and Helpman 1995, Coe et al. 2009, Fracasso and Vitucci Marzetti 2015) and FDI relations (Cipollina et al. 2012, Beugelsdijk et al. 2008, Gorodnichenko et al. 2014, Keller and Yeaple 2009). On the other hand, regional level studies have largely overlooked the role of trade linkages as channels for knowledge spillovers, focusing 
more explicitly on the importance of spatial relations (Gleaser et al. 1992, Frenken et al. 2007, Le Gallo and Dall'Erba, 2008) and, more recently, of assessing the role of various other forms of proximity (Greunz 2003, Paci et al. 2014, Caragliu and Nijkamp 2015). In addition, while different studies discuss the importance of absorptive capacity for an economy to benefit from knowledge spillovers, the effect of spillovers from particularly advanced regions to recipient regions has received little attention.

In order to close the gap in the literature highlighted by our two research questions, we put forward the following three hypotheses. First, the discussion on the theoretical section suggests a positive relation between network-mediated R\&D spillovers and local productivity. Following Coe and Helpman (1995) and Coe et al. (2009), we theorize that regions can access new knowledge assets through its import relations, and that such relations will have a productivity-enhancing effect at local level. Similarly, in light of the debate on different sources of proximity (Boschma 2005, Breschi and Lissoni 2009, Maggioni and Uberti 2009, Maggioni et al. 2007), we expect that intense co-patenting cooperation, as a proxy for relational proximity, will lead to substantial knowledge spillovers, thus having a positive effect on regional productivity.

Hypothesis 1a: The level of productivity in region $\mathrm{R}$ is positively related to the level of $R \& D$ in regions from which $R$ imports.

Hypothesis 1b: The level of productivity in region $\mathrm{R}$ is positively related to the level of $R \& D$ in regions which $\mathrm{R}$ patents with.

To address our second research question, a second set of hypotheses specifically takes into account the relations with regions that are at the forefront in terms of innovative and technological capabilities. Given the great amount of knowledge resources that most advanced regions are bound to have, being connected via import or co-patenting relations with top innovators may provide privileged access to highly valuable knowledge assets. 
Hypothesis 2a: The positive relation between the level of productivity in region $\mathrm{R}$ and the level of $R \& D$ in regions which $\mathrm{R}$ import from is stronger, if the trade partner regions are innovation leaders.

Hypothesis 2b: The positive relation between the level of productivity in region $\mathrm{R}$ and the level of $R \& D$ in regions which $R$ patents with is stronger, if the co-patenting partner regions are innovation leaders.

Finally, given the potential conditioning role of absorptive capacity (Cohen and Levinthal 1990), we expect that regions with higher levels of human capital will be better able to profit from highly advanced knowledge spilling over through trade and co-patenting networks.

Hypothesis 3: The positive relation between the level of productivity in region $\mathrm{R}$ and the $R \& D$ spillovers from trade and co-patenting with highly advanced partners is conditional on higher level of absorptive capacity.

\section{Modeling, methodology and data sources}

We model the level of productivity ${ }^{3}$ in region $r$ as a function of its own R\&D expenses and the R\&D of its neighbors and partners, weighted by import and copatenting intensity. Unlike in previous studies (Coe and Helpman 1995, Coe et al. 2009, Maggioni et al. 2007), we study the effects of spillovers deriving from two different network channels simultaneously and extensively controlling for spatial effects. We test the three hypotheses put forward in the previous section resorting to three panel data models.

The baseline model, reported in Equation 1, is used to estimate the impact of network spillovers on the level of regional productivity while controlling for spatial relations (Hypothesis 1a and 1b):

\footnotetext{
${ }^{3}$ The choice of studying regional productivity levels rather than growth is made in consideration of the economic recession characterizing the period of analysis and the limited number of years available in our sample. This choice is not uncommon in the literature, as in the case of Coe and Helpman (1995), Coe et al. (2009), and Fracasso and Vitucci-Marzetti (2015).
} 


$$
\begin{aligned}
\log _{-} T F P_{r, t}= & \alpha_{r}+\tau_{t}+\beta \log R \& D_{r, t-1}+\delta \boldsymbol{W} \log R \& D_{r, t-1}+\delta \boldsymbol{T} \log R \& D_{r, t-1}+ \\
& \delta \boldsymbol{P} \log R \& D_{r, t-1}+\gamma \text { Controls }_{r, t-1}+\lambda \boldsymbol{W} \varepsilon_{r, t}+u_{r, t}
\end{aligned}
$$

where $\log _{-} T F P_{r, t}$ represents the level of total factor productivity in region $r$ at time $t$ (in logs) and $\boldsymbol{W} \log R \& D_{r, t-1}$ is the distance-weighted per capita $\mathrm{R} \& \mathrm{D}, \boldsymbol{T} \log R \& D_{r, t-1}$ captures the import-mediated spillovers, and $\boldsymbol{P} \log R \& D_{r, t-1}$ refers to co-patentingmediated effects. In order to fully control for spatial dependence, the error terms is split in a spatially lagged term $\left(\lambda \boldsymbol{W} \varepsilon_{r, t}\right)$ and in the residuals $\left(u_{r, t}\right)$. Finally, $\alpha_{r}$ and $\tau_{t}$ represent the cross-sectional and time fixed effects.

Hypotheses $2 \mathrm{a}$ and $2 \mathrm{~b}$ consider the heterogeneity in the effects due to relations with most knowledge-endowed regions. To capture the potential spillovers deriving from network relations with technological leaders, we compute two new variables, $\boldsymbol{T E} \log R \& D_{r, t}$ and $\boldsymbol{P E} \log R \& D_{r, t}$, which capture the intensity of trade and copatenting linkages between the most advanced regions and linking-in regions ${ }^{4}$. To guarantee some degree of heterogeneity, we decide not to apply the same transformation to $\boldsymbol{W} \log R \& D_{r, t}$. In Equation 2, the terms $\boldsymbol{T} \log R \& D_{r, t}$ and $\boldsymbol{P} \log R \& D_{r, t}$ are substituted by the newly computed variables $\left(\boldsymbol{T} \boldsymbol{E} \log R \& D_{r, t}\right.$ and $\left.\boldsymbol{P E} \log R \& D_{r, t}\right)$.

$$
\begin{aligned}
\log _{-} T F P_{r, t}= & \alpha_{r}+\tau_{t}+\beta \log R \& D_{r, t-1}+\delta \boldsymbol{W} \log R \& D_{r, t-1}+\delta \boldsymbol{T E} \log R \& D_{r, t-1}+ \\
& \delta \boldsymbol{P E} \log R \& D_{r, t-1}+\gamma \text { Controls }_{r, t-1}+\lambda \boldsymbol{W} \varepsilon_{r, t}+u_{r, t},
\end{aligned}
$$

In the last specification, we introduce a term interacting the import-weighted (or copatenting-weighted ${ }^{5}$ ) level of $R \& D$ with the level of human capital in the region Ter_H $K_{r, t}$. We do this both for the variables capturing the general trade and copatenting relations (Equation 3) and for those focused on relations with most advanced regions. In this way, we can consider whether stronger capabilities are

\footnotetext{
${ }^{4}$ Linking-in regions may of any type, i.e., other advanced regions, innovation followers, or less developed areas.

${ }^{5}$ For sake of brevity, only the model referring to import relations is reported in Equations 3 and 4.
} 
required to profit from relations to most technological leaders, as we theorize in Hypothesis $3^{6}$.

$$
\begin{gathered}
\log _{-} T F P_{r, t}=\alpha_{r}+\tau_{t}+\beta \log R \& D_{r, t-1}+\delta \boldsymbol{W l o g} R \& D_{r, t-1}+\delta \boldsymbol{T} \log R \& D_{r, t-1}+ \\
\delta \boldsymbol{P} \log R \& D_{r, t-1}+\varphi \boldsymbol{T} \log R \& D_{r, t-1} * T e r_{-} H K_{r, t-1}+\gamma \operatorname{Controls}_{r, t-1}+\lambda \boldsymbol{W} \varepsilon_{r, t}+ \\
u_{r, t}, \\
\log _{-} T F P_{r, t}=\alpha_{r}+\tau_{t}+\beta \log R \& D_{r, t-1}+\delta \boldsymbol{W} \log R \& D_{r, t-1}+\delta \boldsymbol{T} \boldsymbol{E} \log R \& D_{r, t-1}+ \\
\delta \boldsymbol{P E} \log R \& D_{r, t-1}+\varphi \boldsymbol{T} \boldsymbol{E} \log R \& D_{r, t-1} * T e r_{-} H K_{r, t-1}+\gamma \text { Controls } s_{r, t-1}+ \\
\lambda \boldsymbol{W} \varepsilon_{r, t}+u_{r, t},
\end{gathered}
$$

\section{Construction of the weight matrices}

A crucial step in our analysis is to construct the weight matrices to track the intensity of the spatial and network relations between regional economies. Unlike other contributions (Jaffe et al. 1993, Bloom et al. 2013, Lychagin et al. 2016), we follow the spatial econometric literature in computing our weight matrices (Ertur and Koch 2011).

Starting from geographical relations, the literature on spatial knowledge spillovers suggests that knowledge exchanges usually take place within boundaries of 200-300 km (Bottazzi and Peri 2002, Crescenzi and Rodriguez-Pose 2011). To ensure the capture of most knowledge flows across space, we construct the spatial matrix $\mathbf{W}$, using Eurostat geographical data, on the basis of the following definition:

$$
\boldsymbol{W}_{i, j}=\left\{\begin{array}{c}
d_{i j}^{-1}, \text { if } 0<d_{i j} \leq d \\
0, \text { otherwise }
\end{array}\right.
$$

where, $d_{i j}$ represents the distance between the centroids of regions $i$ and $j$, while $d$ represents the threshold of maximum distance we allow for. In other words, for every region, we define as spatially related two region located within a $300 \mathrm{~km}$ radius. Additionally, to account for the fact that greater distances reduce knowledge

\footnotetext{
${ }^{6}$ Because of potential collinearity issues, we do not include both interaction terms at the same time.
} 
exchanges, the entries in the spatial matrix will take the value of the inverse of the distance between the neighboring regional centroids (Elhorst 2014). Finally, as is customary in spatial econometrics (LeSage and Pace 2009), the spatial matrix is rowstandardized.

To capture the strength of trade relations, we use the intensity of import for intermediate goods between each pair of European regions. The Planbureau voor de Leefomgeving (PBL) has computed the yearly trade flows among EU regions for six main sectors, for the period 2000-2010 (Thissen et al. 2016; for a technical description, see Thissen et al. 2014a, 2014b). In order to exploit the broad sectoral categories offered by the data, we construct three import weight matrices, one for all sectors (matrix $\mathbf{T}$ below), one for trade in more advanced sectors (matrix $\mathbf{A}$ ) encompassing chemicals, petroleum, electronics, etc., and one for less advanced sectors (matrix $\mathbf{L}$ below), capturing imports in agriculture, leather, food and beverages industries. The import matrices used in our analysis are computed as follows:

$$
\boldsymbol{T}_{i, j}=\frac{I \_2000 \_2003_{i j}}{\sum_{r} I_{-} 2000 \_2003_{i j}}
$$

where $I_{-} 2000_{-} 2003_{i, j}$ is the value at constant prices of imports in intermediate goods that region $i$ imported from region $j$ between 2000 and 2003. When building our import intensity matrices, we try to limit the concerns for potential endogeneity between trade intensity and economic performance in the following ways. First, as clearly shown in Equation 6, we consider only import data on years that are antecedent to the period considered in our study, so to ensure that the intensity in trade is not driven by regional performance. Second, as single-year trade flows may not offer an accurate picture as for import intensity, we approximate a measure of import stock by summing different yearly import flows. Finally, as for the $\mathbf{W}$ matrix, we row-standardize the trade matrix (Lumenga-Neso et al. 2005).

The matrix $\mathbf{P}$, capturing cross-regional patent collaboration, is constructed using the OECD REGPAT database, which contains detailed information on patent cooperation between inventors residing in different regions. From the raw data, only information 
on co-patenting relations involving more than one European region between 1988 and 2003 is used. An equal share of each of these patents is allocated across the different inventors, before aggregating the patent counts to regional level. Regionalized information on co-patents is then used to compute the weight matrix as shown in Equation 7.

$$
\boldsymbol{P}_{i, j}=\frac{\text { share_pat_1988_2003 }{ }_{i j}}{\sum_{r} \text { share } \_ \text {pat } \_1988 \_2003_{i j}}
$$

As in the case of trade, we use information on the years before 2004 to reduce the concern for endogeneity. As for the spatial and import matrices, the co-patenting matrix is row-standardized.

In addition to concerns regarding endogeneity, a second issue we consider is the overlap between spatial proximity and other channels of knowledge transmission, due to the fact that trade and co-patenting relations are facilitated when actors are located physically close to one another (Caragliu and Nijkamp 2015). The previous literature has dealt with this issue in different ways, for instance combining the different matrices in one (Hazir et al. 2014) or setting to zero the entries for the cells in the network matrices that have non-zero values in the spatial matrix (Maggioni et al. 2007). A closer inspection to our data however provides reassuring evidence. As reported in Table 1, the highest average row-wise correlation (49\%) between the weight matrices is found between the spatial matrix $\mathbf{W}$ and the co-patenting matrix $\mathbf{P}$. Even in this case, however, the correlation does not appear to be particularly worrisome.

\begin{tabular}{lccccccc}
\hline \multicolumn{7}{l}{ Table 1: Row-wise correlation among weight matrices } \\
\hline \multicolumn{1}{c}{} & W-T & W-A & W-L & W-P & T-P & A-P & L-P \\
\hline Min. & -0.06183 & -0.11556 & -0.02039 & -0.04347 & -0.0217 & -0.04258 & -0.02246 \\
1st Quart. & 0.08422 & -0.01285 & 0.26642 & 0.34333 & 0.1279 & 0.0346 & 0.26364 \\
Median & 0.19771 & 0.07265 & 0.41972 & 0.52198 & 0.2326 & 0.1314 & 0.41942 \\
Mean & 0.23825 & 0.11435 & 0.41659 & 0.48778 & 0.2815 & 0.17641 & 0.42233 \\
3rd Quart. & 0.37167 & 0.20059 & 0.58147 & 0.66504 & 0.4114 & 0.27169 & 0.58681 \\
Max & 0.80552 & 0.68881 & 0.91811 & 0.98005 & 0.9222 & 0.9253 & 0.99516 \\
\hline
\end{tabular}


Finally, our last two sets of hypotheses consider the case of relations with top regions, from which we hypothesize a greater quantity and better quality of spillovers can be obtained. To this aim, we consider the position of regions in the per capita distribution of patents for the period 1988-2003, and define as innovation leaders those regions in the top quartile of the distribution ${ }^{7}$.

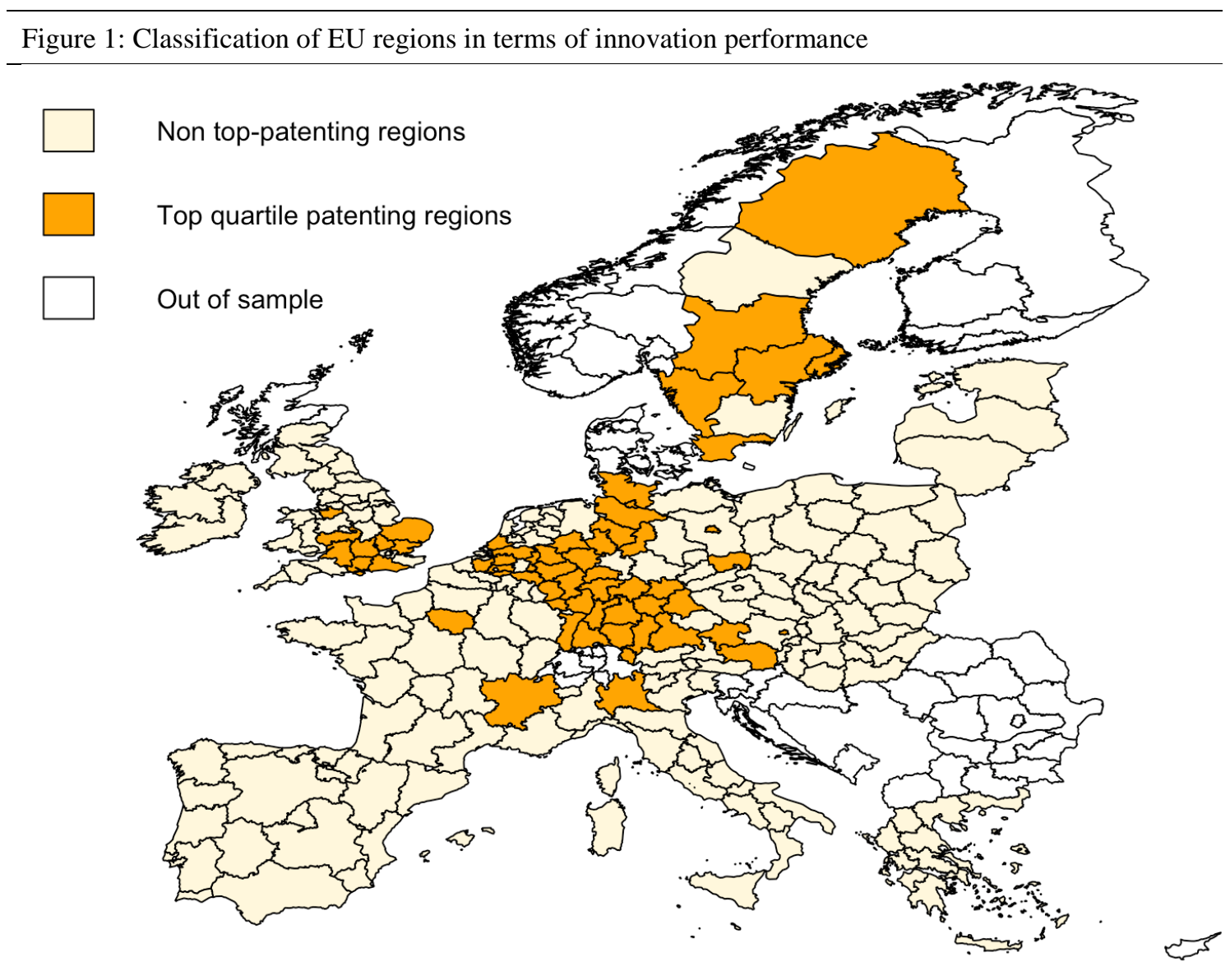

Figure 1 represents the geographical distribution of regions categorized as "Innovation Leaders" (orange). Most of advanced regions are located in the core of Europe, between Southeast England, and the North of Italy, with the greatest concentration in Germany and in Sweden.

\section{$\underline{\text { Data and sources }}$}

\footnotetext{
${ }^{7}$ Cortinovis and Van Oort (2015) divided regions in three technological regimes on the basis of a previous classification by Wintijes and Hollanders (2011). Using the same approach to identify the regions with higher knowledge and technological endowment, by considering regions in our sample belonging to the "high technological regime" as areas particularly rich in knowledge and technologies, leads to comparable results.
} 
In addition to the data provided Eurostat for the spatial matrix and PBL for trade flows and the OECD REGPAT for the co-patenting matrix, we construct our database using information from Cambridge Econometrics (CE) and Eurostat. More precisely, we estimate our dependent variable - the regional level of Total Factor Productivity (TFP - tfp) - by taking the residuals from the following model:

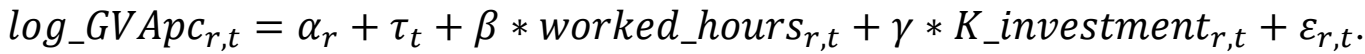

In the model above, the number of hours worked per capita (worked_hours (w,t $_{-}$) captures the amount of labour employed in region $r$ at time $t$. Besides, following Beugelsdijk et al. (2015), we estimate the stock of capital $\left(K_{-}\right.$investment $\left._{r, t}\right)$, starting from gross fixed capital formation and applying the permanent inventory method.

Our main variables of interest are the level of $R \& D$ of each region as well as the network-weighted levels of R\&D. As for the former, Eurostat provides information on the level of R\&D in each region. We therefore use the log of R\&D per capita in PPS $(R \& D p c)$ to construct our other main explanatory variables. More precisely, as spatially and network-weighted measures of $R \& D$, which we use as a proxy for knowledge spillovers, we interact the row-standardized weight matrices with the vector of $R \& D p c$. Equation 9 shows the formula for the spatially weighted $R \& D$ level, and we apply the same procedure for matrices T, A, L, P, TE, AE and PE.

$$
\boldsymbol{W} \log R \& D_{r, t}=\boldsymbol{W}^{*} \log R \& D_{r, t} .
$$

In addition to these explanatory variables, we include different control variables (Controls $_{r, t}$ in Equations 1-3). Based on data from Eurostat, US $H K$ and Te $H K$ measure the share of the workforce with upper-secondary and tertiary education to control for the levels and quality of human capital endowment within each region. Additionally, when testing Hypothesis 3, Te $H K$ interacts with network-weighted $\mathrm{R} \& \mathrm{D}$ measures ${ }^{8}$. We include in all specifications four more control variables computed from the CE database. As is customary in the literature on agglomeration economies, we include a measure of population density (Popd) to control for the

${ }^{8}$ Both $T e r H K$ and the weighted measures of R\&D are mean-centered before estimating Eq. 3 and 4. 
heterogeneity between highly urbanized and rural areas. We also include a variable approximating $^{9}$ the stock of foreign population in the region (For. Pop.), in order to partially control for migration, another important channel of knowledge diffusion (Breschi and Lissoni 2009, Miguelez and Moreno 2015, Hornung, 2010). Finally, to partially control for the economic structure of regions, we include the variables Share Agr and Share Manuf capturing the share of worked hours in manufacturing over the total number of hours worked.

In conclusion, our dataset contains information on 233 European regions at the NUTS 2 level, for a period of 9 years (2004-2012). Because our dataset has been built using different data sources, some regions and countries cannot be included in the analysis. While most of EU-27 regions are included, a lack of data on trade flows and copatenting forces us to exclude Danish, Finnish, Bulgarian and Romanian regions. Additionally, because network data are not regionalized for Slovenia, we must use information on the whole country.

\section{$\underline{\text { Descriptive statistics }}$}

Tables 3 and 4 report the summary statistics and the correlation across the variable included in the models. While most of the cells in Table 4 have the expected magnitude and size, some of the correlation scores are especially interesting. In particular, the correlation between the levels of R\&D at local, space-mediated and network-mediated levels are relatively strong. This suggests that regions highly investing in research and development tend to be proximate both in a geographical and network sense.

\footnotetext{
${ }^{9}$ Eurostat does not provide information on foreign population at regional level. In order to overcome this issue we took the foreign population at country level and redistribute it according to the share of national population accruing to each region.
} 
Table 3: Descriptive statistics

\begin{tabular}{llccccc}
\hline VARIABLES & \multicolumn{1}{c}{ Source } & $\mathrm{N}$ & mean & $\mathrm{sd}$ & $\min$ & $\max$ \\
\hline TFP & Own calc. & 1,864 & -0.0238 & 0.503 & -1.474 & 1.022 \\
Pop. Density & EUROSTAT & 1,864 & 5.087 & 1.132 & 1.129 & 9.159 \\
For. Pop. & EUROSTAT & 1,864 & 8.861 & 0.998 & 5.394 & 10.75 \\
Share Agr. & CE & 1,864 & 0.0627 & 0.0575 & 0.000193 & 0.401 \\
Share Manuf. & CE & 1,864 & 0.184 & 0.0694 & 0.0364 & 0.499 \\
Sec. HK & EUROSTAT & 1,864 & 0.443 & 0.132 & 0.0924 & 0.775 \\
Ter. HK & EUROSTAT & 1,864 & 0.233 & 0.0784 & 0.0668 & 0.646 \\
R\&D pc & EUROSTAT & 1,864 & 5.519 & 1.036 & 1.872 & 7.812 \\
W-R\&D pc & EUROSTAT & 1,864 & 5.493 & 0.941 & 0 & 7.037 \\
T-R\&D pc & EUROSTAT & 1,864 & 6.203 & 0.275 & 4.965 & 6.676 \\
A-R\&D pc & EUROSTAT & 1,864 & 6.281 & 0.225 & 5.444 & 6.772 \\
P-R\&D pc & EUROSTAT & 1,864 & 6.143 & 0.814 & 0 & 7.156 \\
TE-R\&D pc & EUROSTAT & 1,864 & 6.635 & 0.116 & 6.307 & 6.989 \\
AE-R\&D pc & EUROSTAT & 1,864 & 6.672 & 0.12 & 6.352 & 7.103 \\
PE-R\&D pc & EUROSTAT & 1,864 & 6.525 & 1.177 & 0 & 7.427 \\
Number of reg1 & & 233 & & & & \\
Years & & $(2004-2012)$ & & & & 0 \\
\hline & & & & & & \\
\hline
\end{tabular}

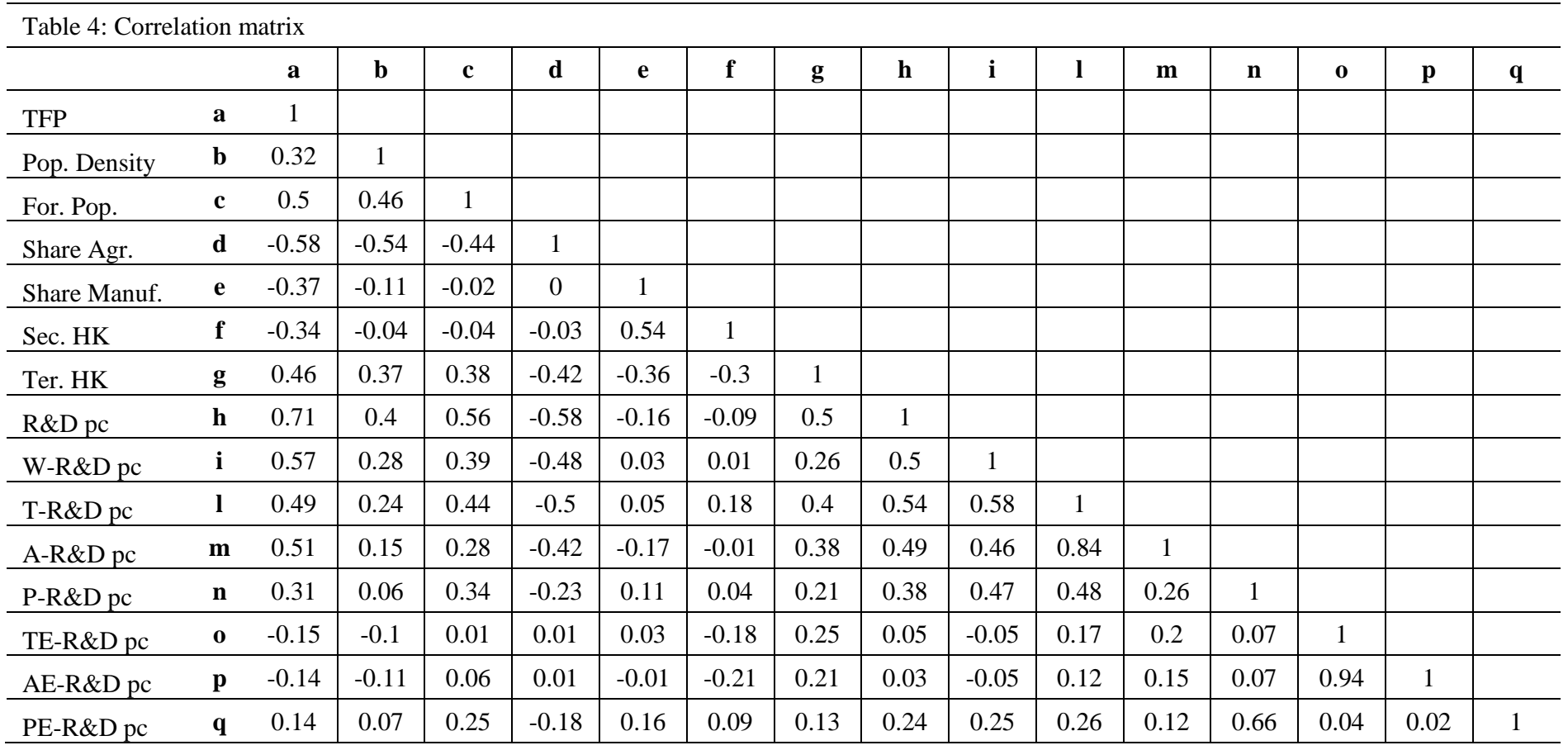


In addition to check the correlation among the spatial and network-weighted R\&D measures, Figure 2 represents graphically the relations between two main variables of

Figure 2: Nework vs spatially weighted R\&D measures

Panel A: R\&D weighted by total trade (T-R\&D pc) vs spatially weighted R\&D (W-R\&D pc)

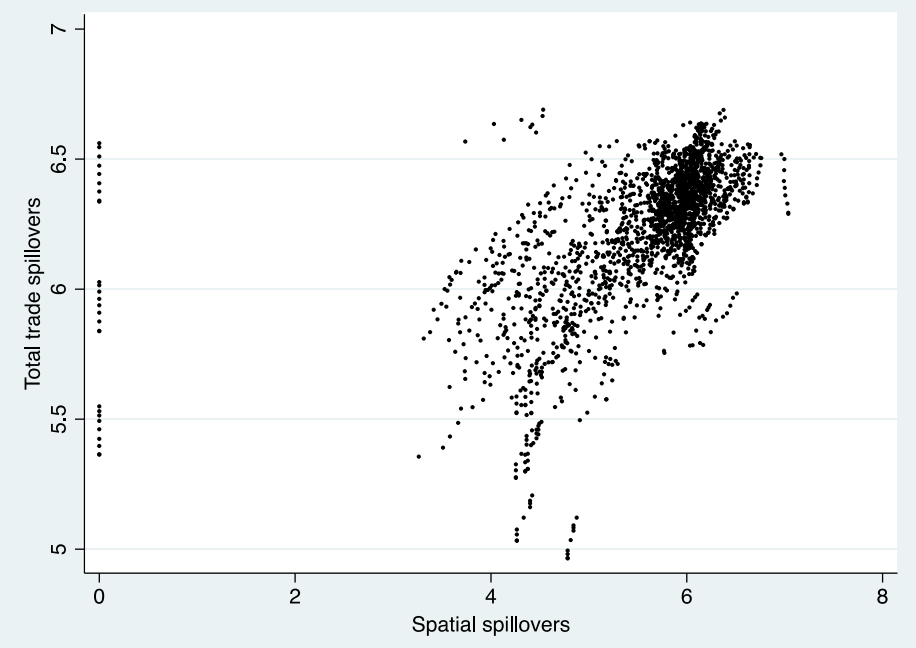

Panel B: R\&D weighted by co-patenting (P-R\&D pc) vs spatially weighted R\&D (W-R\&D pc)

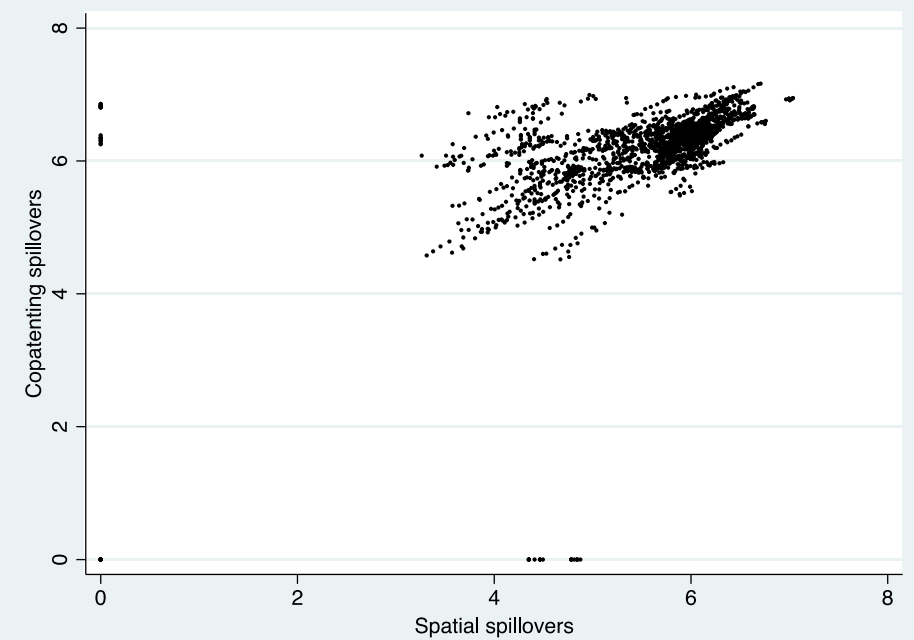

interests $(T-R \& D p c$ and $P-R \& D p c)$ and the spatial R\&D spillovers $(W-R \& D p c)$. Both graphs show a clear positive relation between the two variables. Three main points deserve to be noticed. First, assuming that R\&D expenditures increased overtime, trade-mediated spillovers appear to be subject to greater change than both spatial and co-patenting relations, as suggested by the more marked vertical orientation of the scatterplot. In other words, whereas for most of EU regions spatial spillovers changed to a limited extent only, import mediated spillovers have markedly 
increased. The same is not true for co-patenting spillovers, whose change is more aligned with the change in spatially weighted R\&D. Second, as also shown by Table 3, co-patenting spillovers are more concentrated and less spread along the vertical axis. to have. Lastly, some regions have do not receive any spillovers due to either remoteness (GR43, SE33), lack of network connections (GR41, GR22), or both (GR42).

\begin{tabular}{|c|c|c|c|c|c|c|c|c|}
\hline VARIABLES & $\begin{array}{l}\text { Standard } \\
\text { panel }\end{array}$ & Space & $\begin{array}{c}\text { Total } \\
\text { Trade }(\mathrm{T}) \\
\end{array}$ & $\begin{array}{l}\text { Advanced } \\
\text { Trade (A) } \\
\end{array}$ & $\begin{array}{l}\text { Low-tech } \\
\text { Trade (L) }\end{array}$ & $\begin{array}{c}\text { Co-patenting } \\
(\mathrm{P})\end{array}$ & $\begin{array}{l}\text { All Net } \\
(\mathrm{TP})\end{array}$ & $\begin{array}{l}\text { All Net } \\
\text { (AP) }\end{array}$ \\
\hline \multirow[t]{2}{*}{ Pop. Density } & $-0,0823$ & $-0,022$ & 0,0211 & 0,0146 & 0,000265 & 0,0128 & 0,0482 & 0,0474 \\
\hline & $(0.209)$ & $(0.280)$ & $(0.289)$ & $(0.291)$ & $(0.285)$ & $(0.275)$ & $(0.283)$ & $(0.285)$ \\
\hline \multirow[t]{2}{*}{ For. Pop. } & 0,0946 & 0,0379 & $-0,0171$ & $-0,0076$ & 0,00894 & 0,00211 & $-0,0435$ & $-0,0411$ \\
\hline & $(0.259)$ & $(0.295)$ & $(0.304)$ & $(0.304)$ & $(0.302)$ & $(0.286)$ & $(0.295)$ & $(0.295)$ \\
\hline \multirow[t]{2}{*}{ Share Agr. } & $-0.593 * * *$ & $-0,0853$ & $-0,0734$ & $-0,0742$ & $-0,0813$ & $-0,0756$ & $-0,0651$ & $-0,0644$ \\
\hline & $(0.184)$ & $(0.137)$ & $(0.139)$ & $(0.139)$ & $(0.137)$ & $(0.123)$ & $(0.124)$ & $(0.124)$ \\
\hline \multirow[t]{2}{*}{ Share Manuf. } & $-0.492 * * *$ & $-0.246^{*}$ & $-0.264 *$ & $-0.263^{*}$ & $-0.249 *$ & $-0.253^{*}$ & $-0.268 * *$ & $-0.269 * *$ \\
\hline & $(0.181)$ & $(0.138)$ & $(0.138)$ & $(0.138)$ & $(0.137)$ & $(0.134)$ & $(0.135)$ & $(0.134)$ \\
\hline \multirow[t]{2}{*}{ Sec. HK } & $0.231 * * *$ & $0.123^{*}$ & $0.130^{*}$ & $0.131^{*}$ & $0.122 *$ & 0,117 & $0.123^{*}$ & $0.125^{*}$ \\
\hline & $(0.0806)$ & $(0.0743)$ & $(0.0738)$ & $(0.0735)$ & $(0.0740)$ & $(0.0726)$ & $(0.0725)$ & $(0.0720)$ \\
\hline \multirow[t]{2}{*}{ Ter. HK } & 0,175 & 0,094 & 0,0988 & 0,101 & 0,0928 & 0,0915 & 0,0956 & 0,098 \\
\hline & $(0.111)$ & $(0.0827)$ & $(0.0836)$ & $(0.0831)$ & $(0.0827)$ & $(0.0810)$ & $(0.0819)$ & $(0.0812)$ \\
\hline \multirow[t]{2}{*}{$\mathrm{R} \& \mathrm{D} p \mathrm{pc}$} & $0.0361 * * *$ & 0,011 & 0,0105 & 0,0112 & 0,0103 & 0,00785 & 0,00746 & 0,00801 \\
\hline & $(0.00866)$ & $(0.00726)$ & $(0.00718)$ & $(0.00715)$ & $(0.00743)$ & $(0.00715)$ & $(0.00710)$ & $(0.00704)$ \\
\hline \multirow[t]{2}{*}{ W-R\&D pc } & & $0.0633 * * *$ & $0.0544 * *$ & $0.0569 * *$ & $0.0577 * *$ & 0,0297 & 0,0229 & 0,0238 \\
\hline & & $(0.0237)$ & $(0.0243)$ & $(0.0236)$ & $(0.0262)$ & $(0.0248)$ & $(0.0253)$ & $(0.0248)$ \\
\hline \multirow[t]{2}{*}{ T-R\&D pc } & & & 0,116 & & & & 0,0991 & \\
\hline & & & $(0.0958)$ & & & & $(0.0901)$ & \\
\hline \multirow[t]{2}{*}{$A-R \& D$ pc } & & & & $0.152 *$ & & & & $0.148^{*}$ \\
\hline & & & & $(0.0855)$ & & & & $(0.0851)$ \\
\hline \multirow[t]{2}{*}{ L-R\&D pc } & & & & & 0,0278 & & & \\
\hline & & & & & $(0.0472)$ & & & \\
\hline \multirow[t]{2}{*}{$\mathrm{P}-\mathrm{R} \& \mathrm{D}$ pc } & & & & & & $0.102 * * *$ & $0.0988 * * *$ & $0.100 * * *$ \\
\hline & & & & & & $(0.0337)$ & $(0.0345)$ & $(0.0341)$ \\
\hline \multirow[t]{2}{*}{ lambda } & & $0.667 * * *$ & $0.669 * * *$ & $0.670 * * *$ & $0.666 * * *$ & $0.659 * * *$ & $0.661 * * *$ & $0.662 * * *$ \\
\hline & & $(0.0442)$ & $(0.0425)$ & $(0.0422)$ & $(0.0440)$ & $(0.0459)$ & $(0.0442)$ & $(0.0438)$ \\
\hline Observations & 1,864 & 1,864 & 1,864 & 1,864 & 1,864 & 1,864 & 1,864 & 1,864 \\
\hline R-squared & 0,119 & 0,463 & 0,397 & 0,462 & 0,48 & 0,289 & 0,23 & 0,273 \\
\hline Number of reg1 & 233 & 233 & 233 & 233 & 233 & 233 & 233 & 233 \\
\hline Region FE & YES & YES & YES & YES & YES & YES & YES & YES \\
\hline Year FE & YES & YES & YES & YES & YES & YES & YES & YES \\
\hline R-Squared (w) & 0,119 & 0,0829 & 0,0435 & 0,0366 & 0,0725 & 0,0792 & 0,0491 & 0,0404 \\
\hline Log-likelihood & 4002 & 4328 & 4331 & 4334 & 4328 & 4344 & 4346 & 4349 \\
\hline
\end{tabular}




\section{Econometric analysis}

Tables 5 and 6 report the estimated coefficients for our models. Each column of each table refers to a different specification, for which the weight matrix used is indicated in the header of the column.

The first column of Table 4 shows the baseline mode that only includes a spatially weighted error term, the only coefficient that is strongly positive and significant. This result suggests a strong pattern of spatial dependency in regional TFP. The second column includes, along with the spatial error term, a spatially weighted measure of $R \& D$. This latter coefficient is strongly positive and significant, suggesting that an increase in the $\mathrm{R} \& \mathrm{D}$ expenditures in geographically proximate regions is positively related to future level of TFP in the focal region. An increase by 1 percent increase in $W-R \& D p c$ increases the level of productivity by around 0.06 percent. With respect to the control variables we notice most of them, throughout the specifications, do not appear to significantly relate on regional TFP, with the only exception of Manuf. share. Whereas this may be surprising, we suspect that the reason is the inclusion of the fixed effects and limited overtime variation that characterizes these variables.

Looking at the effects of trade-weighted R\&D spillovers (columns 3 to 5), only R\&D spillovers deriving from trade in more advanced goods $(A-R \& D p c)$ have an impact on local TFP, while the coefficients for $T-R \& D p c$ and $L-R \& D p c$ are not different from zero. In terms of magnitudes of the coefficients, the effect of $A-R \& D p c$ is stronger than the of $W-R \& D p c$ : a 1 percent increase in $A-R \& D p c$ would lead to an increase in TFP of 0.15 percent. Besides, it is interesting to notice that in column 4 , the spatially-weighted $R \& D$ term is still positive significant, though slightly smaller than in column 2 . The inclusion of co-patenting mediated $R \& D$ slightly change the pictured presented so far by Table 5. Similar to the case of trade, the estimated coefficient for $P-R \& D p c$ appears to be substantial, with a 1 percent increase in copatenting spillovers leading to an increase in TFP of 0.1 percent. Besides, once the spillovers from co-patenting relations are accounted for (columns 5, 6 and 7), the coefficient of $W-R \& D p c$ becomes insignificant, while the spatial error terms reduces 
in size. This would suggest that a substantial portion of what the spatially-weighted R\&D term actually captures co-patenting relationships, as also indicated by other literature (Miguelez and Moreno 2015). The last column of Table 5 shows that the effect $A-R \& D p c$ is robust to the inclusion of $P-R \& D p c$ leaves virtually unchanged the coefficient of $A-R \& D p c$.

\begin{tabular}{|c|c|c|c|c|c|c|}
\hline VARIABLES & $\begin{array}{c}\text { Total } \\
\text { Trade (TE) }\end{array}$ & $\begin{array}{c}\text { Advanced } \\
\text { Trade (AE) }\end{array}$ & $\begin{array}{l}\text { Low-tech } \\
\text { Trade (LE) }\end{array}$ & $\begin{array}{l}\text { Co-patenting } \\
(\mathrm{PE})\end{array}$ & $\begin{array}{l}\text { All Net } \\
\text { (TEPE) }\end{array}$ & $\begin{array}{l}\text { All Net } \\
\text { (AEPE) }\end{array}$ \\
\hline \multirow[t]{2}{*}{ Pop. Density } & -0.00512 & 0.0409 & -0.0206 & -0.0186 & -0.00269 & 0.0414 \\
\hline & $(0.288)$ & $(0.319)$ & $(0.283)$ & $(0.286)$ & $(0.294)$ & $(0.318)$ \\
\hline \multirow[t]{2}{*}{ For. Pop. } & 0.0274 & -0.0283 & 0.0376 & 0.0329 & 0.0236 & -0.0281 \\
\hline & $(0.302)$ & $(0.331)$ & $(0.298)$ & $(0.301)$ & $(0.308)$ & $(0.331)$ \\
\hline \multirow[t]{2}{*}{ Share Agr. } & -0.0846 & -0.0878 & -0.0858 & -0.0888 & -0.0873 & -0.0861 \\
\hline & $(0.137)$ & $(0.138)$ & $(0.137)$ & $(0.137)$ & $(0.137)$ & $(0.137)$ \\
\hline \multirow[t]{2}{*}{ Share Manuf. } & $-0.264 *$ & $-0.250^{*}$ & $-0.252 *$ & $-0.246^{*}$ & $-0.263^{*}$ & $-0.251 *$ \\
\hline & $(0.140)$ & $(0.138)$ & $(0.140)$ & $(0.138)$ & $(0.140)$ & $(0.138)$ \\
\hline \multirow[t]{2}{*}{ Sec. HK } & 0.120 & 0.114 & $0.123^{*}$ & 0.122 & 0.118 & 0.115 \\
\hline & $(0.0738)$ & $(0.0733)$ & $(0.0742)$ & $(0.0764)$ & $(0.0759)$ & $(0.0750)$ \\
\hline \multirow[t]{2}{*}{ Ter. HK } & 0.0934 & 0.0934 & 0.0960 & 0.0929 & 0.0926 & 0.0939 \\
\hline & $(0.0825)$ & $(0.0836)$ & $(0.0832)$ & $(0.0824)$ & $(0.0822)$ & $(0.0834)$ \\
\hline \multirow[t]{2}{*}{$\mathrm{R} \& \mathrm{D} \mathrm{pc}$} & 0.0110 & 0.0105 & 0.0110 & 0.0110 & 0.0110 & 0.0105 \\
\hline & $(0.00722)$ & $(0.00731)$ & $(0.00724)$ & $(0.00725)$ & $(0.00720)$ & $(0.00730)$ \\
\hline \multirow[t]{2}{*}{ W-R\&D pc } & $0.0624 * * *$ & $0.0612 * * *$ & $0.0633 * * *$ & $0.0626 * * *$ & $0.0619 * *$ & $0.0615 * *$ \\
\hline & $(0.0240)$ & $(0.0237)$ & $(0.0239)$ & $(0.0240)$ & $(0.0244)$ & $(0.0239)$ \\
\hline \multirow[t]{2}{*}{ TE-R\&D pc } & 0.133 & & & & 0.132 & \\
\hline & (0.144) & & & & $(0.142)$ & \\
\hline \multirow[t]{2}{*}{ AE-R\&D pc } & & 0.107 & & & & 0.111 \\
\hline & & $(0.127)$ & & & & $(0.131)$ \\
\hline \multirow[t]{2}{*}{ LE-R\&D pc } & & & 0.0446 & & & \\
\hline & & & $(0.133)$ & & & \\
\hline \multirow[t]{2}{*}{ PE-R\&D pc } & & & & 0.00799 & 0.00608 & -0.00409 \\
\hline & & & & $(0.0475)$ & $(0.0471)$ & $(0.0489)$ \\
\hline \multirow[t]{2}{*}{ lambda } & $0.671 * * *$ & $0.668 * * *$ & $0.669 * * *$ & $0.667 * * *$ & $0.671 * * *$ & $0.667 * * *$ \\
\hline & $(0.0435)$ & $(0.0441)$ & $(0.0443)$ & $(0.0441)$ & $(0.0435)$ & $(0.0443)$ \\
\hline Observations & 1,864 & 1,864 & 1,864 & 1,864 & 1,864 & 1,864 \\
\hline R-squared & 0.453 & 0.290 & 0.456 & 0.459 & 0.446 & 0.288 \\
\hline Number of reg1 & 233 & 233 & 233 & 233 & 233 & 233 \\
\hline Region FE & YES & YES & YES & YES & YES & YES \\
\hline Year FE & YES & YES & YES & YES & YES & YES \\
\hline R-Squared (w) & 0.0368 & 0.0437 & 0.0606 & 0.0800 & 0.0364 & 0.0435 \\
\hline Log-likelihood & 4329 & 4329 & 4328 & 4328 & 4329 & 4329 \\
\hline
\end{tabular}


In Table 6, we address our second research question, looking exclusively at network relations with most advanced regions in terms of technology and innovation. Our hypotheses are that connections to these regions can be particularly beneficial due to the high quality and quantity of knowledge resources they have accumulated. The first three columns of Table 6 relate to trade relations, the fourth column to co-patenting relations and the fifth and sixth one look at spatial, trade and co-patenting relations jointly. Unlike in Table 5, the coefficient of $W-R \& D p c$ is positive significant in all the specifications. Differently, no significant effect is found for any kind of trademediated R\&D from most innovative regions. Finally, a positive significant effect is found for $P E-R \& D p c$; while this coefficient is slightly smaller than those reported in Table 6, it suggests that relations to technological leaders via co-patenting have a direct effect on local productivity. Overall, the results in Table 6 are not fully in line with hypotheses $2 \mathrm{a}$ and $2 \mathrm{~b}$ : relations to most advanced regions, while having a direct effect in the case of $P E-R \& D p c$, do not necessarily imply any stronger effect in terms of R\&D spillovers on local productivity.

As discussed in the theoretical framework, spillovers from advanced regions may require particularly high levels of absorptive capacity for regions to benefit from them. We test this hypothesis through Model 3 and 4, whose estimates are reported in Table 7. Results in Table 7 highlight new relevant insights, in particular with respect to the role of trade. Like in the previous estimates, the coefficients are insignificant. However, the interaction term $T E-R \& D p c * L . T e_{-} H K$ is now positive significant, suggesting that the effect of trade from most technologically advanced regions varies positively for higher levels of human capital. The same holds true for $A E-R \& D p c *$ $L . T e \_H K$. This is made more evident by comparing the graph reported in Panels A and $\mathrm{B}$ of Figure 3. As the left-hand graph show, the effect of $T E-R \& D p c$ on TFP is positive and different from zero (right-hand side vertical axis) for regions with a level of human capital (horizontal axis and bar distribution in the background with mean centered at 0) at around .14, i.e. two standard deviations above the mean (see Table 3). Panel B shows a similar patterns, with the effect of $A E-R \& D p c$ becoming positive and different from zero for marginally lower levels of human capital. It is also interesting to notice that, at least for regions with very high levels of human capital, the marginal effects of $T E-R \& D p c$ appear to exceed those deriving from $A E-R \& D p c$. Going back to Table 7, unlike TE-R\&D pc *L.Te_HK and AE-R\&D pc*L.Te_HK, 
no significant interaction effect is found for $A-R \& D p c, P-R \& D p c$ and $P E-R \& D p c$. However, the effects of $R \& D$ spillovers from trade in advanced inputs $(A-R \& D p c)$ and co-patenting relations $(P-R \& D p c)$ remain comparable to those reported in Table 5.

\begin{tabular}{|c|c|c|c|c|c|c|c|c|}
\hline VARIABLES & $\begin{array}{c}\text { Total } \\
\text { Trade (TP) } \\
\end{array}$ & $\begin{array}{c}\text { Total } \\
\text { Trade (TEPE) } \\
\end{array}$ & $\begin{array}{l}\text { Advanced } \\
\text { Trade (AP) }\end{array}$ & $\begin{array}{c}\text { Advanced } \\
\text { Trade (AEPE) }\end{array}$ & $\begin{array}{l}\text { Co-patenting } \\
(\mathrm{PT})\end{array}$ & $\begin{array}{c}\text { Co-patenting } \\
\text { (PETE) }\end{array}$ & $\begin{array}{c}\text { Co-patenting } \\
(\mathrm{PA})\end{array}$ & $\begin{array}{c}\text { Co-patenting } \\
\text { (PEAE) }\end{array}$ \\
\hline \multirow{2}{*}{ Ter. HK } & 0.0782 & 0.0376 & 0.0890 & 0.0264 & 0.100 & 0.105 & 0.110 & 0.1000 \\
\hline & $(0.0842)$ & $(0.0794)$ & $(0.0823)$ & $(0.0817)$ & $(0.0806)$ & $(0.0800)$ & $(0.0779)$ & $(0.0831)$ \\
\hline \multirow{2}{*}{$\mathrm{R} \& \mathrm{D} \mathrm{pc}$} & 0.00875 & $0.0140 * *$ & 0.00888 & $0.0131 *$ & 0.00805 & 0.00933 & 0.00886 & 0.00909 \\
\hline & $(0.00698)$ & $(0.00707)$ & $(0.00705)$ & $(0.00714)$ & $(0.00718)$ & $(0.00779)$ & $(0.00717)$ & $(0.00783)$ \\
\hline \multirow{2}{*}{ W-R\&D pc } & 0.0265 & $0.0674 * * *$ & 0.0261 & $0.0729 * * *$ & 0.0215 & $0.0609 * *$ & 0.0228 & $0.0604 * *$ \\
\hline & $(0.0254)$ & $(0.0244)$ & $(0.0248)$ & $(0.0238)$ & $(0.0256)$ & $(0.0246)$ & $(0.0250)$ & $(0.0241)$ \\
\hline \multirow{2}{*}{$\mathrm{T}-\mathrm{R} \& \mathrm{D} \mathrm{pc}$} & 0.119 & & & & 0.107 & & & \\
\hline & $(0.0893)$ & & & & $(0.0893)$ & & & \\
\hline \multirow{2}{*}{ TE-R\&D pc } & & 0.203 & & & & 0.134 & & \\
\hline & & $(0.141)$ & & & & $(0.141)$ & & \\
\hline \multirow{2}{*}{$\mathrm{A}-\mathrm{R} \& \mathrm{D} \mathrm{pc}$} & & & $0.154^{*}$ & & & & $0.162 *$ & \\
\hline & & & $(0.0855)$ & & & & $(0.0844)$ & \\
\hline \multirow{2}{*}{$\mathrm{AE}-\mathrm{R} \& \mathrm{D}$ pc } & & & & 0.129 & & & & 0.104 \\
\hline & & & & $(0.133)$ & & & & $(0.131)$ \\
\hline \multirow{2}{*}{$\mathrm{P}-\mathrm{R} \& \mathrm{D} \mathrm{pc}$} & $0.0997 * * *$ & & $0.103 * * *$ & & $0.105^{* * *}$ & & $0.108 * * *$ & \\
\hline & $(0.0348)$ & & $(0.0345)$ & & $(0.0339)$ & & $(0.0337)$ & \\
\hline \multirow{2}{*}{ PE-R\&D pc } & & 0.0132 & & 0.00102 & & 0.00776 & & $-3.86 e-05$ \\
\hline & & $(0.0471)$ & & $(0.0491)$ & & $(0.0473)$ & & $(0.0492)$ \\
\hline \multirow{2}{*}{ T-R\&D pc*Ter. HK } & 0.231 & & & & & & & \\
\hline & $(0.191)$ & & & & & & & \\
\hline \multirow{2}{*}{ TE-R\&D pc*Ter. HK } & & $0.935^{* * *}$ & & & & & & \\
\hline & & $(0.261)$ & & & & & & \\
\hline \multirow{2}{*}{ A-R\&D pc*Ter. HK } & & & 0.152 & & & & & \\
\hline & & & $(0.203)$ & & & & & \\
\hline \multirow[t]{2}{*}{ AE-R\&D pc*Ter. HK } & & & & $0.821 * * *$ & & & & \\
\hline & & & & $(0.228)$ & & & & \\
\hline \multirow{2}{*}{ P-R\&D pc*Ter. HK } & & & & & 0.0888 & & 0.0972 & \\
\hline & & & & & $(0.0776)$ & & $(0.0790)$ & \\
\hline \multirow{2}{*}{ PE-R\&D pc*Ter. HK } & & & & & & -0.0452 & & -0.0368 \\
\hline & & & & & & $(0.0493)$ & & $(0.0504)$ \\
\hline \multicolumn{9}{|l|}{ lambda } \\
\hline Observations & 1,864 & 1,864 & 1,864 & 1,864 & 1,864 & 1,864 & 1,864 & 1,864 \\
\hline R-squared & 0.230 & 0.102 & 0.283 & 0.210 & 0.204 & 0.413 & 0.222 & 0.325 \\
\hline Number of reg1 & 233 & 233 & 233 & 233 & 233 & 233 & 233 & 233 \\
\hline Region FE & YES & YES & YES & YES & YES & YES & YES & YES \\
\hline Year FE & YES & YES & YES & YES & YES & YES & YES & YES \\
\hline R-Squared (w) & 0.0479 & 0.0378 & 0.0400 & 0.0595 & 0.0463 & 0.0343 & 0.0362 & 0.0444 \\
\hline Log-likelihood & 4348 & 4352 & 4350 & 4350 & 4348 & 4330 & 4351 & 4330 \\
\hline
\end{tabular}


Figure 3: Marginal Effects (the dashed lines indicates 10\% confidence interval)

Panel A: Marginal Effect of $T E-R \& D p c$

\section{Robustness checks on causality}

Endogeneity is an obvious concern when studying the relation between $R \& D$ spillovers and local productivity. Whereas the use of panel settings allow us to control for the potential bias of time-invariant omitted variables and the inclusion of lagged regressors somewhat reduce the problem of reverse causality, the coefficients discussed in the previous may still be affected by endogeneity.

To correctly identify the effects of R\&D on local productivity, the instrument should be correlated to current $R \& D$ expenditure but not with current productivity. For doing this, we exploit historical data on regional illiteracy rates (ILLIT) and gross reproduction rates (GRR) in the early 1930s (Kirk 1946). While literacy rates have been used to proxy current quality of local institutions (Tabellini 2010), the level of illiteracy is likely to even better capture the (lack of) propensity to invest in knowledge. Similarly, GRR, a measure of replacement fertility capturing the average number of female newborns per fertile woman, relates to the local ability to invest in human capital. The negative relation between fertility rates, human capital investments is generally accepted ${ }^{10}$ in development economics (Todaro and Smith

\footnotetext{
${ }^{10}$ Todaro and Smith (2011, p. 296) argue that "it is generally agreed that large family size and low incomes restrict the opportunities of parents to educate all their children. At the national level, rapid population growth causes educational expenditures to be spread more thinly, lowering quality for the
} 
2011). We thus expect both the illiteracy rate and GRR to be negatively related to the current level of regional R\&D. Looking at the geographical distribution of current $R \& D$ expenditures, illiteracy rates and infant mortality rates in the 1930s confirms this idea. Generally speaking, regions investing more in $R \& D$ (darker shades in the map in Panel A of Figure 4 below) appear to be closely matched by lower levels of illiteracy and infant mortality (lighter shades in the maps in Panels B and C). A clear negative relation is shown in scatterplots in Figure 5 and 6. Following Bloom et al. (2013), we build the instruments for the space- and network-weighted variables interacting the respective matrix with ILLIT and GRR.

In order for the instruments to be valid, they should not be correlated with current level of productivity. Current productivity dynamics are likely to be influenced by many factors, some of which only slowly changing over time (Tabellini, 2010). However, it is safe to assume our instruments to be exogenous from current productivity dynamics, especially considering the profound economic, cultural, social and political transformation undergone by European societies since the early 1930s.

sake of quantity. This in turn feeds back on economic growth because the stock of human capital is reduced by rapid population growth". 

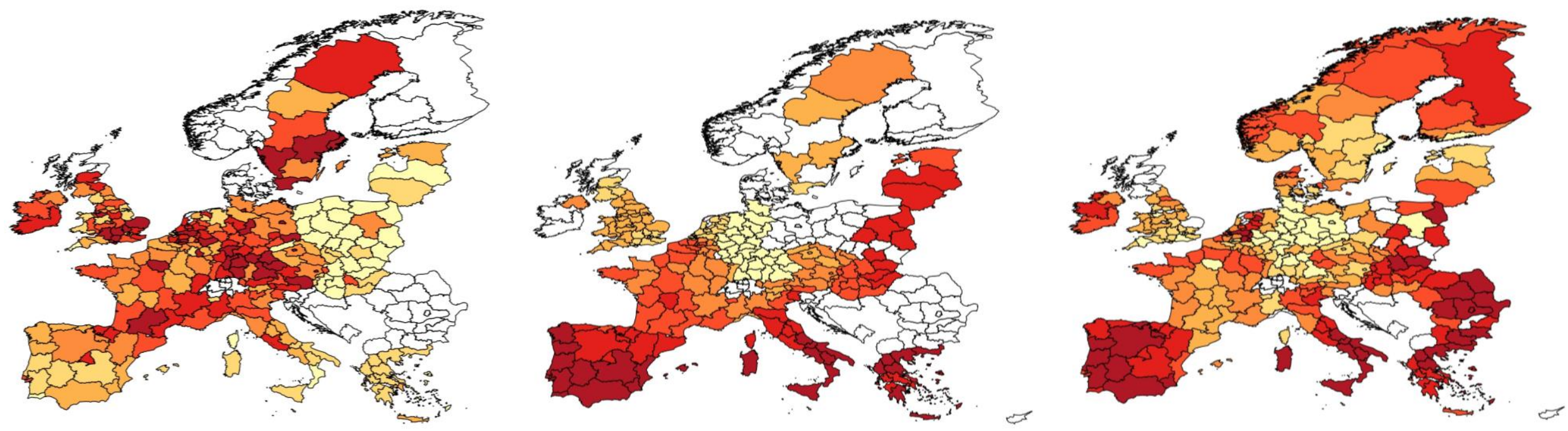


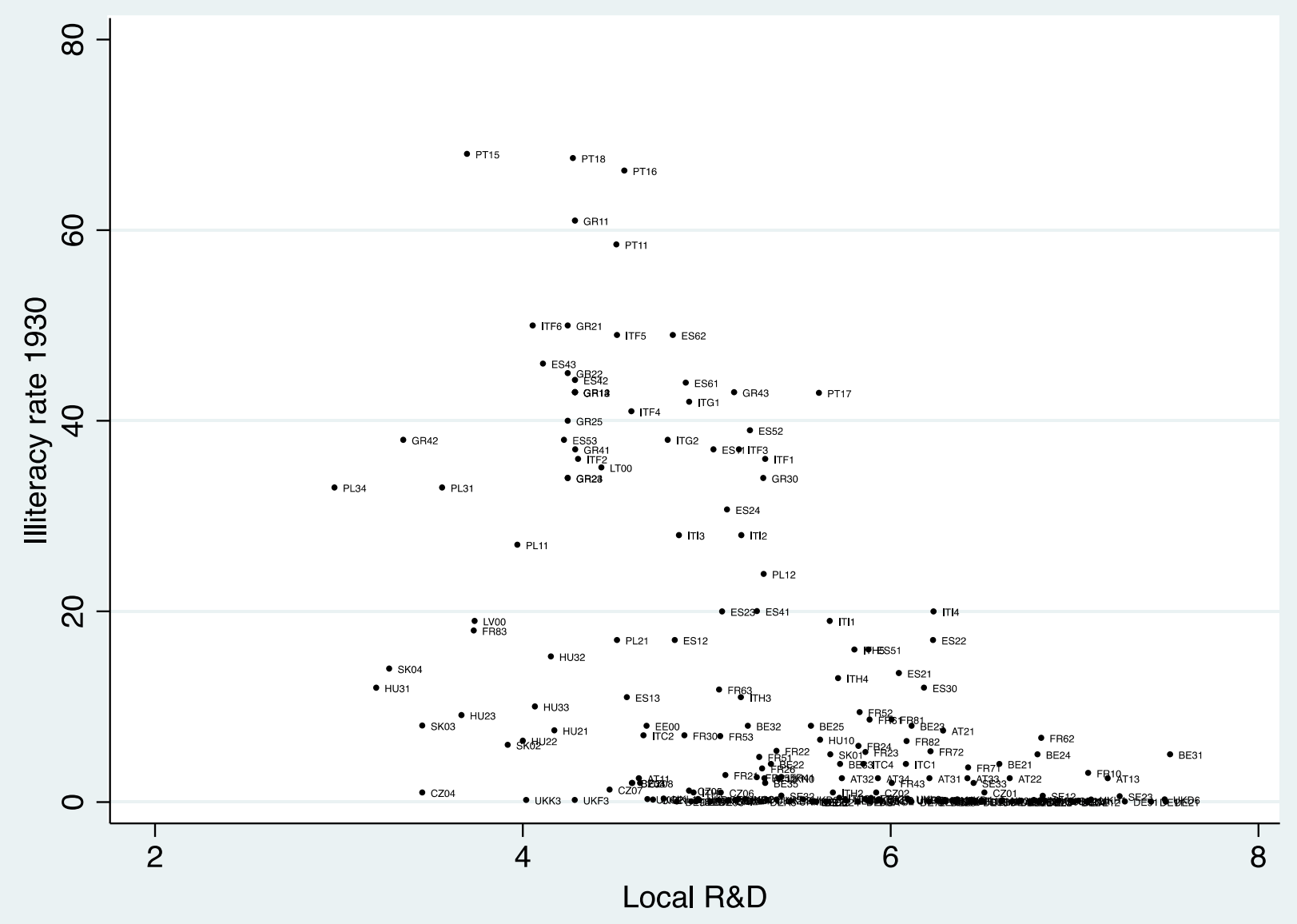




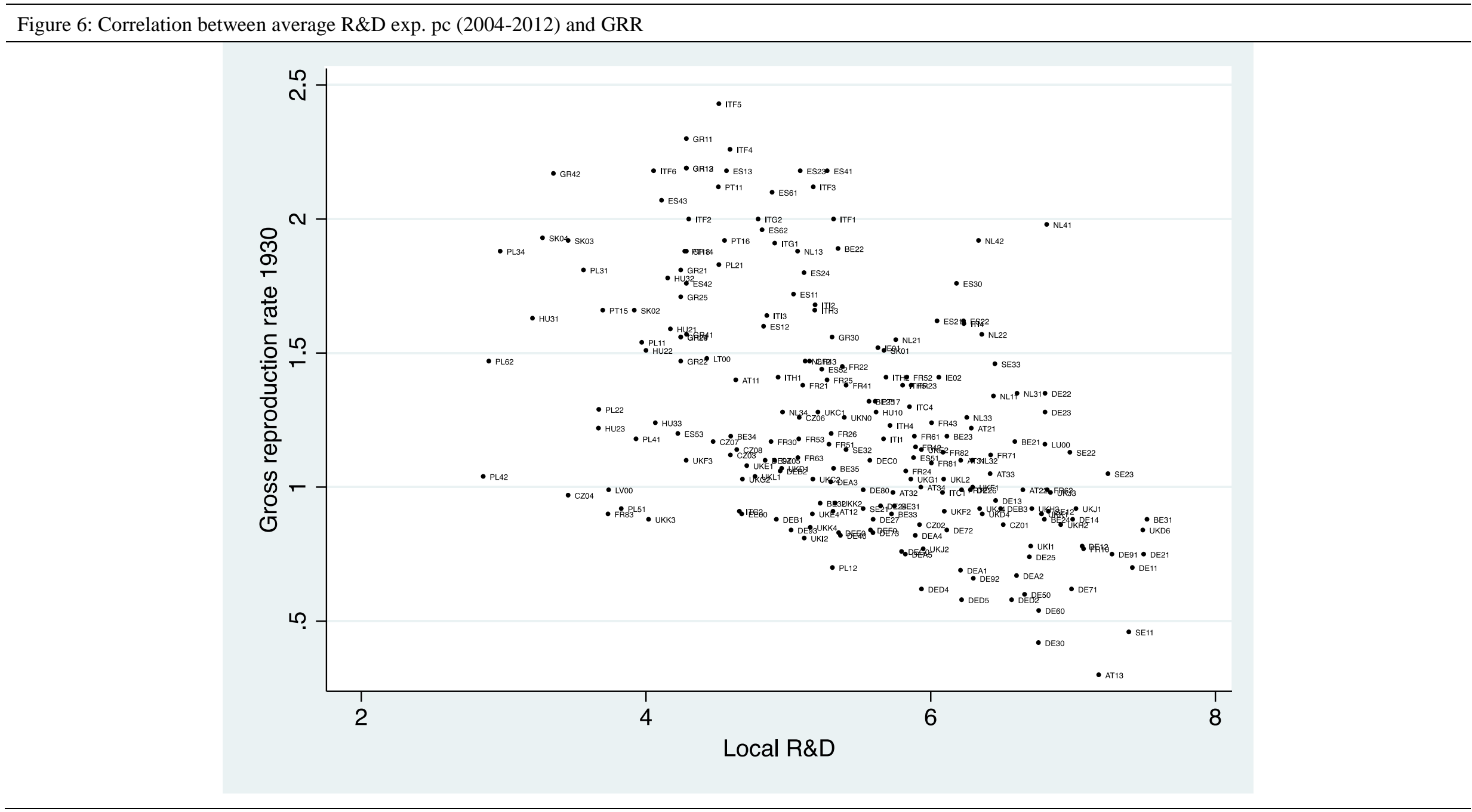


Whereas our illiteracy rates and GRR appear to be promising instruments, we observe them only at one point in time. Instrumental variable estimation in a panel model with fixed effects instead would require an instrument whose overtime variation closely mimic the one of the endogenous variable. As such variable is probably impossible to find, we choose to move from panel to cross-sectional settings and identify the effects of network-mediated R\&D spillovers. Since we can no longer rely on regional fixed effects for capturing time invariant factors affecting regional productivity, we slightly modified the model reported in Equation 1. Firstly, we select as dependent variable the level of regional TFP in 2012. Secondly, we include the 2004 value of the control variables and the network-related R\&D spillovers, used in the previous estimations. To the existing control variables, we add the 2004 level of TFP in order to control for the historical productivity conditions of the regions. Thirdly, given the high collinearity of $R \& D p c$ and $W-R \& D p c$ and their instruments, we sum the two terms and enter them as a single variable. As the spatial weight matrix has all $0 \mathrm{~s}$ in the diagonal, the new variable captures the total effect of $R \& D$ expenditures in the region and in neighboring areas. Fourthly, we include macro-regional dummies (at NUTS1 level) to capture the residual spatial relations of regions, as we cannot include a spatial error term ${ }^{11}$. In mathematical notation, our 2SLS model can be represented as follows:

$$
\begin{aligned}
& \log \_T F P_{r, 2012}=\log _{-} T F P_{r, 2004}+\alpha \log \_t o t_{-} \operatorname{loc} R \& D_{r, 2004}+\delta \boldsymbol{T} \log R \& D_{r, 2004}+ \\
& \theta \boldsymbol{P} \log R \& D_{r, 2004}+\gamma \text { Controls }_{r, 2004}+\varphi N U T S 1_{R}+u_{r} .
\end{aligned}
$$

The second stage results of our IV regressions are reported in Table 8, along with the standard tests for relevance and exogeneity of the instruments. Starting from the bottom part of the table, throughout the 5 specifications, both the tests on the relevance of the excluded instruments and the tests on over-identification provide convincing evidence on the validity of our IV strategy. The only exception is the significant Hansen J test in fifth column of the table. Also, it should be noticed that, of

\footnotetext{
${ }^{11}$ Whereas Stata allows to estimate spatial error IV regressions using - spivreg - , such command does not allow for thorough testing of the validity of the instruments and does not make available the first stage results of the regression. This motivated our decision to drop the spatial error term from the model.
} 
the 233 regions which were included in our panel, around 40 have dropped out from the 2SLS regression due to missing values for the instruments.

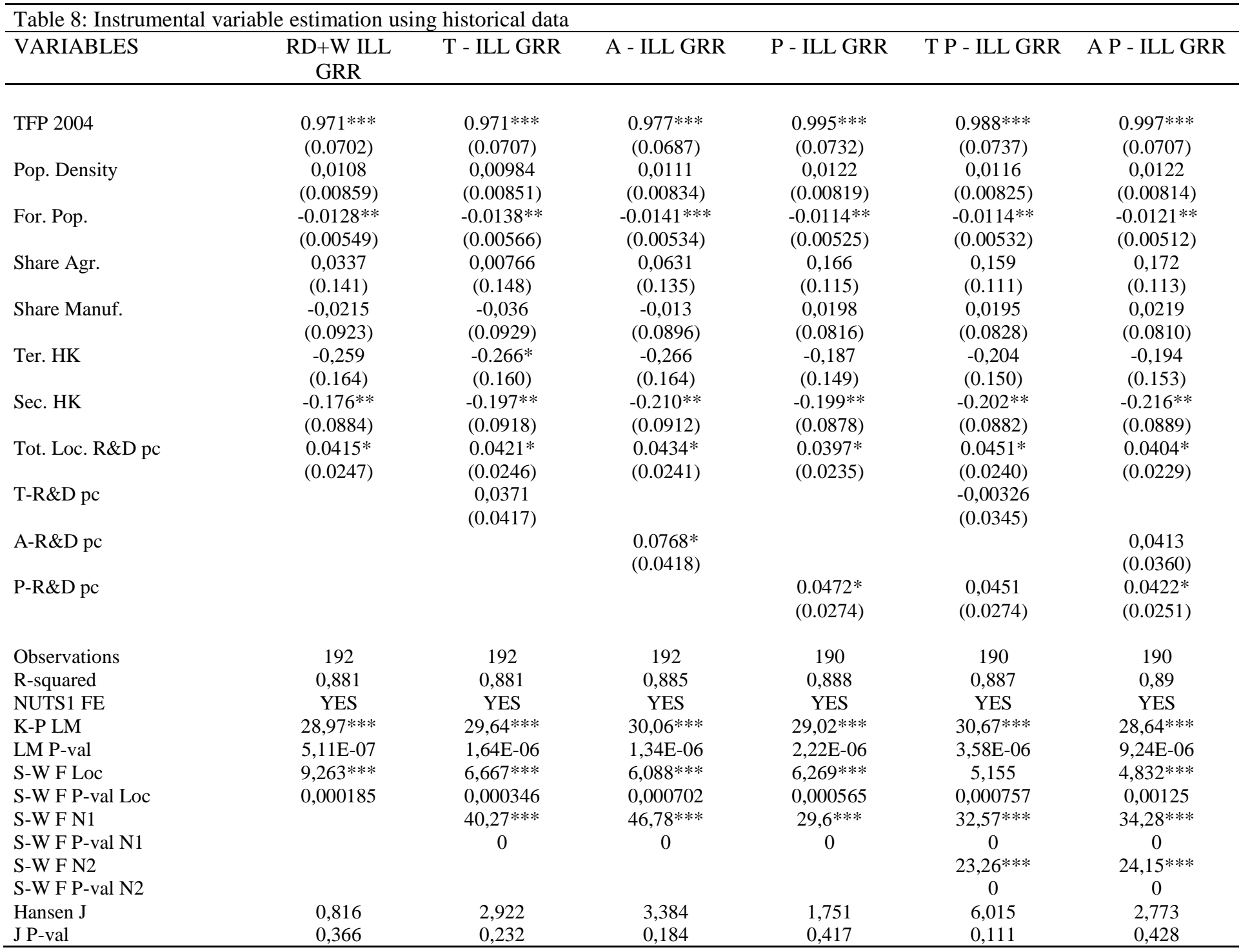

Robust standard errors in parentheses $* * * \mathrm{p}<0.01, * * \mathrm{p}<0.05, * \mathrm{p}<0.1$

When considering the size and significant coefficients of the instrumented variables, we find substantial confirmation of the results reported in Table 4. In particular, along with significant local-spatial $R \& D$ spillovers, the effects of $R \& D$ externalities from network relations are found for both imports of advanced intermediate goods (columns 3 and in Table 7) and co-patenting relations (columns 4 and in Table 7). It is interesting to notice that the sizes of the coefficients in these 2SLS regressions are smaller but comparable to those reported in Tables 4 and 6 . According to our IV estimates, a 1 percent increase in $R \& D$ expenditures in regions from which an 
average region buys advanced intermediate goods induces an increase in the local productivity of 0.08 percent. Similarly, incrementing R\&D expenditures in copatenting partners by 1 percent increases local productivity by 0.04 percent. As in the previous results, $A-R \& D p c$ has a stronger effect than $P-R \& D p c$. The last two columns of Table 7 do not report any significant coefficient for the network-mediated $\mathrm{R} \& \mathrm{D}$ a part from the coefficient for Tot. Loc. $R \& D p c$ which is positive significant. Such imprecise estimates are likely to be due to the high correlation scores among the instruments (see Table 9 in the Appendix) and limited variation in our cross-sectional data.

\section{Conclusions}

The aim of this paper is to contribute to the debate on knowledge spillovers, which involves different sub-disciplines in economics and economic geography. In doing this, we adopt a regional perspective and we assess how the regional level of productivity is affected by $R \& D$ externalities deriving from trade and co-patenting relations with other regions on a European regional scale. The attention devoted to import-mediated R\&D spillover is particularly innovative for the regional economic literature, as it compares the trade networks vis-à-vis other kinds of relations (spatial and co-inventorship). A second, more qualitative contribution of this work relates to the study of the direction of network relations, i.e., import- and co-patenting-mediated relations to regions that are innovation leaders. A third substantial innovation is represented by the instrumental variable strategy, which provides more robust evidence on the causal effects linking network-related R\&D spillovers and local productivity.

After a short review of the extensive literature on knowledge spillovers, we put forward our research questions and hypotheses. First, based on the empirical research on agglomeration economies, we expect R\&D spillovers deriving from network relations to have a strong impact on local productivity (Hypothesis 1a and 1b). Our estimates consistently confirm these hypotheses, especially for what concerns spillovers from advanced imports and spillovers from co-patenting relations. Both these effects find confirmation in our 2SLS estimations. Our expectations on the role of R\&D spillovers from innovation leaders, expressed in Hypotheses $2 a$ and $2 b$ are 
instead not confirmed. According to our estimates, the superior knowledge endowment that top innovating regions have does not necessarily spill over and translate into higher productivity for trade partners and co-inventors. A potential explanation for this, conceptualized in Hypothesis 3, refers to the lack of absorptive capacity in recipient regions. Including an interaction between the network-mediated spillovers with human capital endowments, our analysis suggests that preconditions exist for regions to profit from connections with most advanced areas. Interestingly, knowledge embodied in goods and technologies and diffused via trade seems to be harder to assimilate by recipients, whereas co-patenting spillovers are not influenced by local conditions in terms of absorptive capacity.

Different insights in terms of policy implications can be drawn from the results of our analysis. Our results show that network relations do complement localized knowledge endowments of regions and contribute to a higher levels of productivity. These results are informative in the light of the recent debates concerning restrictions on trade and political decisions on freedom of movements, potentially jeopardizing knowledge collaborations. However, our results also suggest that some conditions may exist for network effects to materialize. In particular, the strongest impact of trade-mediated knowledge spillovers occurs when the receiving region has abundant human capital and knowledge assets. From the one hand, this result indicates the crucial importance of investments in absorptive capacity. From the other hand, our estimates question the applicability of recent European policy initiatives, such as smart specialization opportunities for all regions in Europe. Lagging regions in Europe may not fully benefit from trade relations, as they lack the necessary and dedicated skills and human capital to absorb the knowledge embedded in the networks and put it to use in local productive economies. Instead of regionally spilling over in the networks, valuable knowledge may keep boiling down in the closed "old boys" network of most advanced EU regions (Desdoigts 1999, Hoekman et al. 2009). 


\section{APPENDIX}

Figure 7: Correlation between nework and spatially weighted R\&D measures: advanced trade and space (top), low-tech trade and space (bottom)
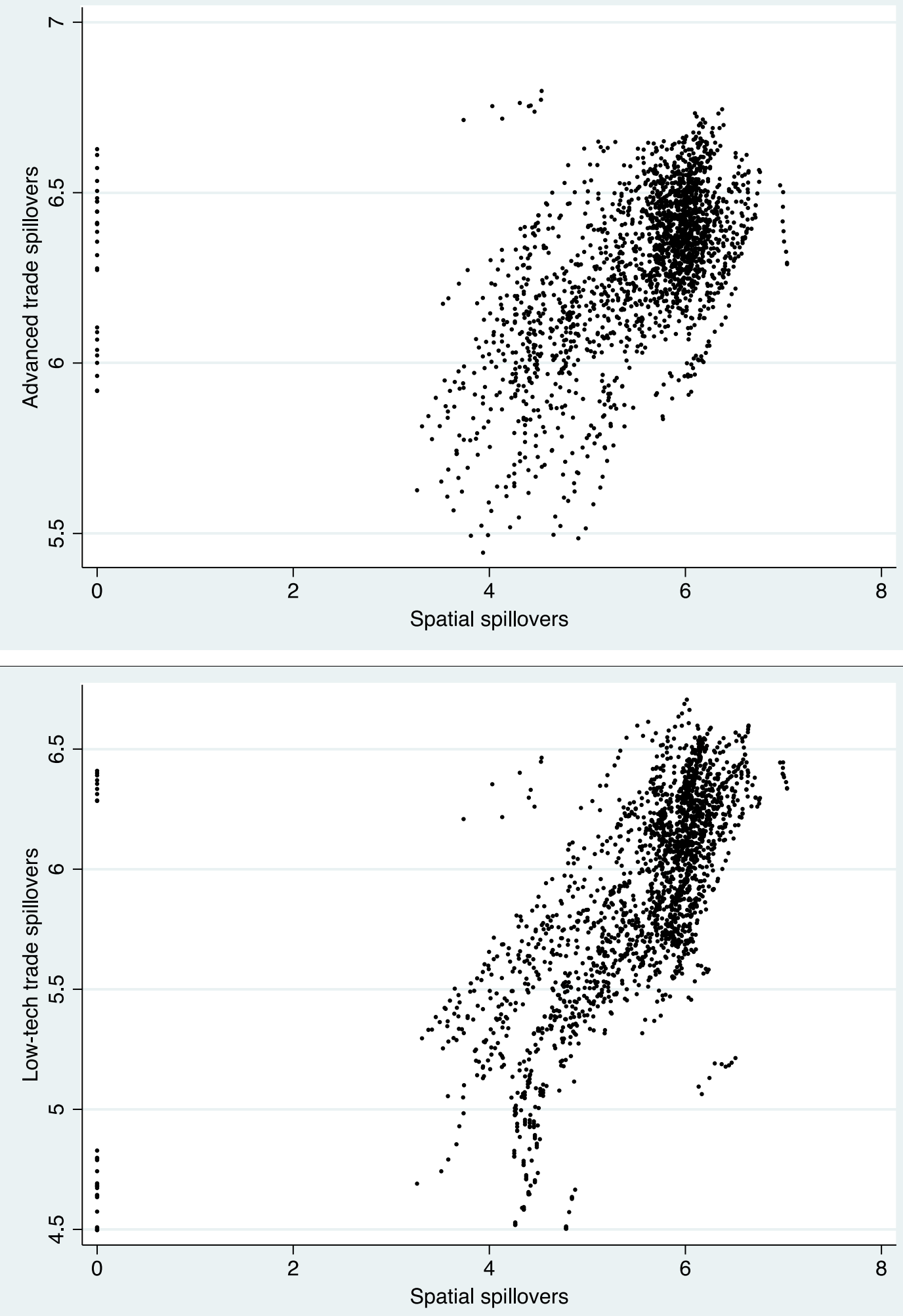
Figure 8: Correlation between nework and spatially weighted R\&D measures: total trade and co-patenting (top), advanced trade and co-patenting (bottom)
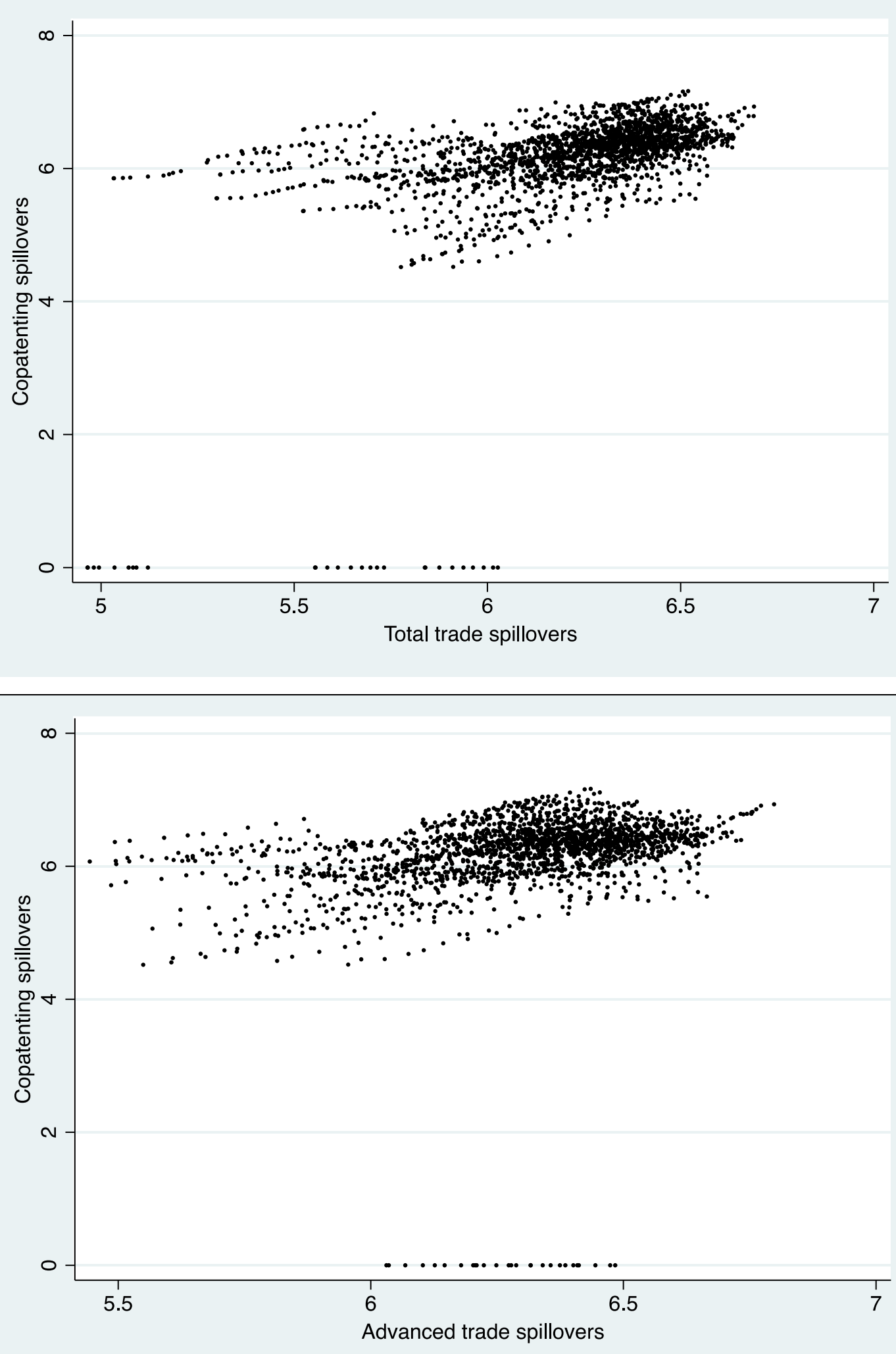
Figure 9: Correlation between Tot. Loc. R\&D pc and ILLIT+W*ILLIT (above), and between Tot. Loc. R\&D pc and GRR+W*GRR (below)
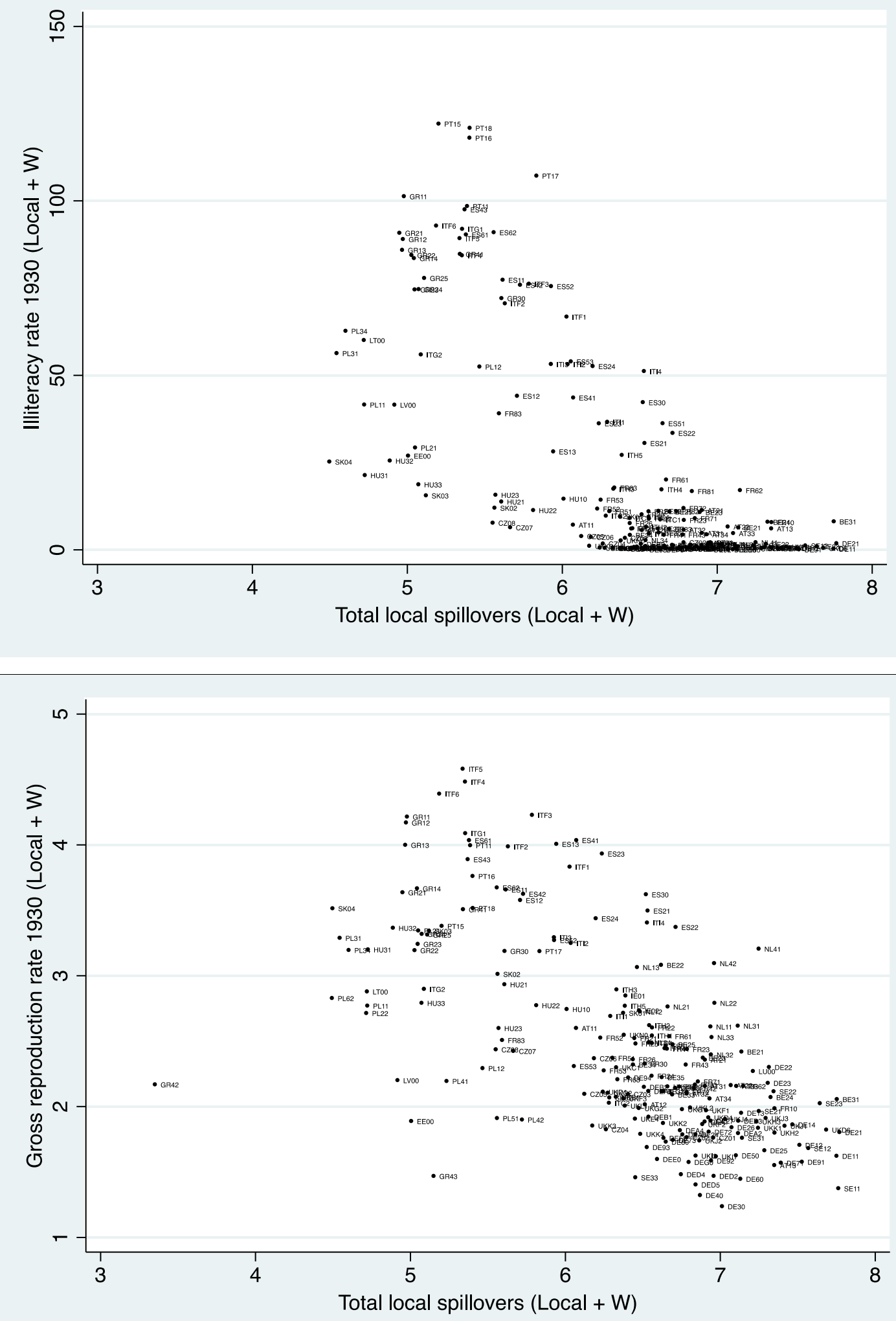


\begin{tabular}{|c|c|c|c|c|c|c|c|c|c|c|c|c|c|c|c|c|}
\hline & & $\mathbf{a}$ & b & c & $d$ & e & $f$ & $\mathbf{g}$ & $\mathbf{b}$ & $i$ & $i$ & $\mathbf{k}$ & 1 & $m$ & & \\
\hline $\mathrm{R} \& \mathrm{D} p \mathrm{c}$ & $\mathbf{a}$ & 1.00 & & & & & & & & & & & & & & \\
\hline ILLIT & b & -0.54 & 1.00 & & & & & & & & & & & & & \\
\hline GRR & c & -0.53 & 0.71 & 1.00 & & & & & & & & & & & & \\
\hline W-R\&D pc & d & 0.53 & -0.57 & -0.48 & 1.00 & & & & & & & & & & & \\
\hline W_ILLIT & e & -0.49 & 0.95 & 0.68 & -0.69 & 1.00 & & & & & & & & & & \\
\hline W-GRR & $\mathbf{f}$ & -0.44 & 0.81 & 0.79 & -0.61 & 0.87 & 1.00 & & & & & & & & & \\
\hline $\mathrm{T}-\mathrm{R} \& \mathrm{D} \mathrm{pc}$ & $\mathbf{g}$ & 0.56 & -0.69 & -0.57 & 0.60 & -0.69 & -0.66 & 1.00 & & & & & & & & \\
\hline T-ILLIT & $\mathbf{h}$ & -0.47 & 0.83 & 0.61 & -0.50 & 0.84 & 0.74 & -0.86 & 1.00 & & & & & & & \\
\hline T_GRR & $\mathbf{i}$ & -0.39 & 0.77 & 0.60 & -0.43 & 0.79 & 0.75 & -0.85 & 0.95 & 1.00 & & & & & & \\
\hline $\mathrm{A}-\mathrm{R} \& \mathrm{D} \mathrm{pc}$ & $\mathbf{j}$ & 0.53 & -0.52 & -0.45 & 0.51 & -0.51 & -0.51 & 0.84 & -0.60 & -0.64 & 1.00 & & & & & \\
\hline A_ILLIT & $\mathbf{k}$ & -0.43 & 0.78 & 0.60 & -0.44 & 0.79 & 0.74 & -0.81 & 0.90 & 0.91 & -0.75 & 1.00 & & & & \\
\hline A-GRR & 1 & -0.33 & 0.65 & 0.48 & -0.35 & 0.66 & 0.63 & -0.75 & 0.77 & 0.89 & -0.77 & 0.89 & 1.00 & & & \\
\hline P-R\&D pc & m & 0.38 & -0.33 & -0.25 & 0.47 & -0.36 & -0.35 & 0.48 & -0.42 & -0.36 & 0.29 & -0.20 & -0.21 & 1.00 & & \\
\hline P-ILLIT & $\mathbf{n}$ & -0.41 & 0.75 & 0.61 & -0.40 & 0.80 & 0.77 & -0.61 & 0.74 & 0.72 & -0.46 & 0.68 & 0.59 & -0.53 & 1.00 & \\
\hline P-GRR & $\mathbf{0}$ & -0.27 & 0.50 & 0.66 & -0.23 & 0.53 & 0.72 & -0.43 & 0.50 & 0.52 & -0.32 & 0.46 & 0.37 & -0.52 & 0.69 & 1.00 \\
\hline
\end{tabular}




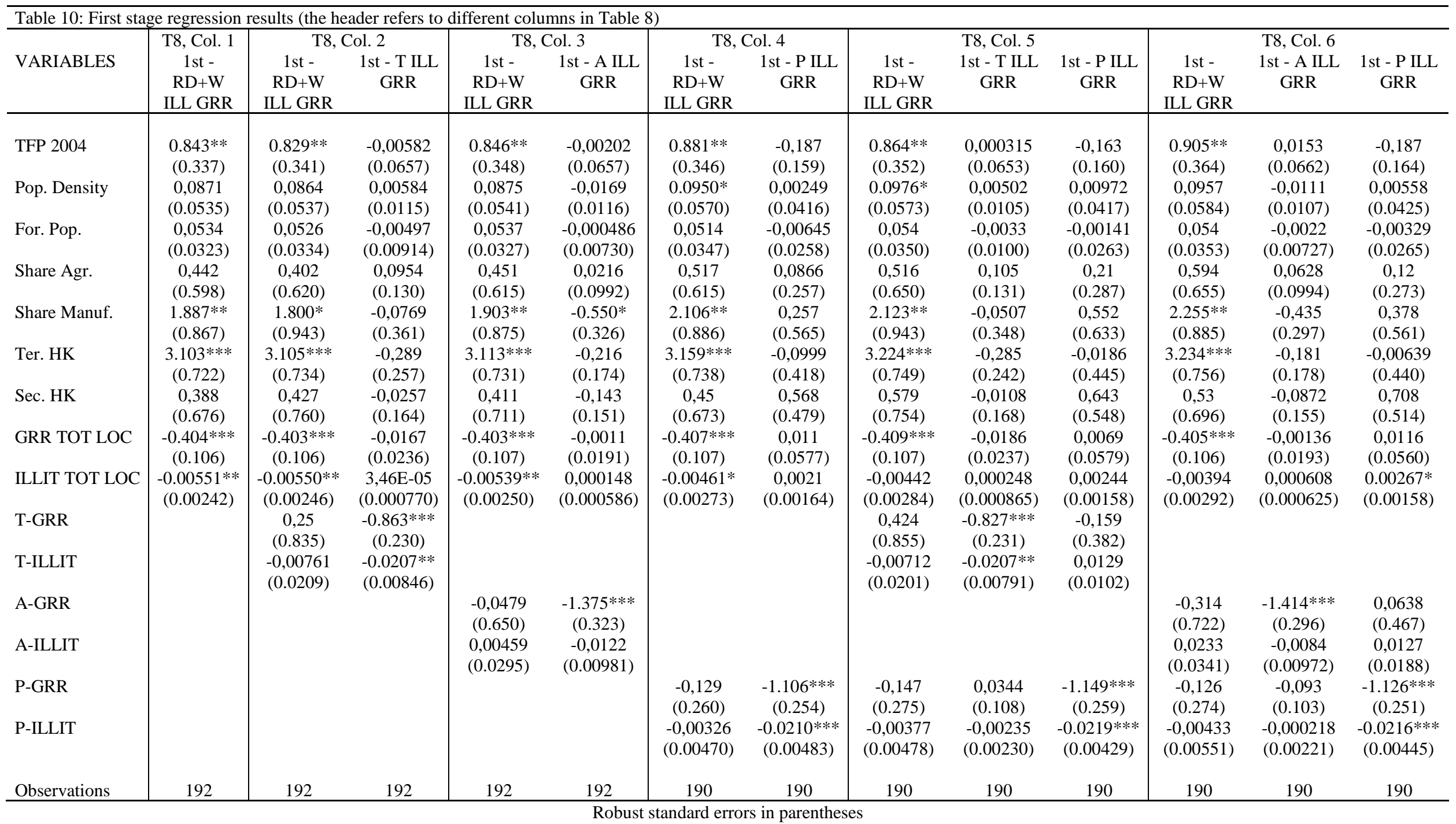


$* * * \mathrm{p}<0.01, * * \mathrm{p}<0.05, * \mathrm{p}<0.1$ 


\begin{tabular}{|c|c|c|c|c|c|c|c|c|}
\hline VARIABLES & $\begin{array}{c}1 \text { st - RD GUF- } \\
\text { No_GUF }\end{array}$ & $\begin{array}{c}\text { 1st - RD+W GUF- } \\
\text { No_GUF }\end{array}$ & $\begin{array}{c}\text { 1st - RD+W GUF- } \\
\text { No_GUF }\end{array}$ & $\begin{array}{l}\text { 1st - T GUF- } \\
\text { No_GUF }\end{array}$ & $\begin{array}{c}\text { 1st - RD+W GUF- } \\
\text { No_GUF }\end{array}$ & $\begin{array}{l}\text { 1st - A GUF- } \\
\text { No_GUF }\end{array}$ & $\begin{array}{c}\text { 1st - RD+W GUF- } \\
\text { No_GUF }\end{array}$ & $\begin{array}{l}\text { 1st - P GUF- } \\
\text { No_GUF }\end{array}$ \\
\hline \multirow[t]{2}{*}{ Pop. Density } & -0.217 & -0.161 & -0.133 & -0.181 & -0.142 & -0.0944 & -0.392 & -0.390 \\
\hline & $(0.838)$ & $(0.582)$ & $(0.562)$ & $(0.145)$ & $(0.563)$ & $(0.182)$ & $(0.616)$ & $(0.351)$ \\
\hline \multirow[t]{2}{*}{ For. Pop. } & 0.102 & -0.0259 & -0.0119 & 0.263 & -0.0241 & 0.0726 & 0.0803 & 0.399 \\
\hline & (1.189) & $(0.840)$ & $(0.821)$ & $(0.191)$ & $(0.823)$ & $(0.204)$ & $(0.818)$ & $(0.473)$ \\
\hline \multirow{2}{*}{ Share Agr. } & $-1.748 * * *$ & $-1.595 * * *$ & $-1.607 * * *$ & $-0.208 * * *$ & $-1.612 * * *$ & -0.0793 & $-1.562 * * *$ & $-0.839 * *$ \\
\hline & $(0.610)$ & $(0.425)$ & $(0.399)$ & $(0.0754)$ & $(0.413)$ & $(0.0733)$ & $(0.455)$ & $(0.367)$ \\
\hline \multirow[t]{2}{*}{ Share Manuf. } & 0.875 & 0.325 & 0.344 & $0.168^{*}$ & 0.353 & 0.0916 & 0.415 & $0.597 * *$ \\
\hline & $(0.771)$ & $(0.457)$ & $(0.440)$ & $(0.0985)$ & $(0.446)$ & $(0.101)$ & $(0.471)$ & $(0.293)$ \\
\hline \multirow{2}{*}{ Ter. HK } & 0.00162 & -0.0991 & -0.0838 & -0.0701 & -0.0914 & -0.0418 & -0.148 & -0.147 \\
\hline & $(0.308)$ & $(0.200)$ & $(0.203)$ & $(0.0629)$ & $(0.201)$ & $(0.0621)$ & $(0.210)$ & $(0.145)$ \\
\hline \multirow[t]{2}{*}{ Sec. HK } & $0.856 * * *$ & $0.527 * * *$ & $0.556 * * *$ & 0.0308 & $0.540 * * *$ & -0.0640 & $0.374^{*}$ & $0.331 * *$ \\
\hline & $(0.272)$ & $(0.167)$ & $(0.156)$ & $(0.0407)$ & $(0.162)$ & $(0.0420)$ & $(0.199)$ & $(0.129)$ \\
\hline GUF R\&D pc & $\begin{array}{c}0.0157 \\
(0.0488)\end{array}$ & & & & & & & \\
\hline No-GUF R\&D pc & $\begin{array}{c}0.0848 * * * \\
(0.0281)\end{array}$ & & & & & & & \\
\hline GUF Loc. R\&D pc & & $\begin{array}{l}0.107 * * \\
(0.0496)\end{array}$ & $\begin{array}{l}0.100 * * \\
(0.0484)\end{array}$ & $\begin{array}{c}0.00650 \\
(0.00848)\end{array}$ & $\begin{array}{l}0.105^{* *} \\
(0.0494)\end{array}$ & $\begin{array}{c}0.00303 \\
(0.00741)\end{array}$ & $\begin{array}{c}0.143 * * * \\
(0.0448)\end{array}$ & $\begin{array}{c}0.0786 * * \\
(0.0376)\end{array}$ \\
\hline No-GUF Loc. R\&D pc & & $\begin{array}{c}0.0951 * * * \\
(0.0299)\end{array}$ & $\begin{array}{l}0.110^{* * * *} \\
(0.0283)\end{array}$ & $\begin{array}{c}0.0188 * * * \\
(0.00554)\end{array}$ & $\begin{array}{c}0.0989 * * * \\
(0.0297)\end{array}$ & $\begin{array}{c}0.00756 * * \\
(0.00361)\end{array}$ & $\begin{array}{l}0.182 * * * \\
(0.0647)\end{array}$ & $\begin{array}{c}0.0599 * * * \\
(0.0152)\end{array}$ \\
\hline GUF T-R\&D pc & & & 0.0509 & $0.0588 * * *$ & & & & \\
\hline No-GUF T-R\&D pc & & & $\begin{array}{c}(0.0468) \\
-0.0806 * * \\
(0.0378)\end{array}$ & $\begin{array}{l}(0.0185) \\
0.00323 \\
(0.0100)\end{array}$ & & & & \\
\hline \multirow{3}{*}{$\begin{array}{l}\text { GUF A-R\&D pc } \\
\text { No-GUF A-R\&D pc }\end{array}$} & & & & & 0.0392 & $0.0574 * * *$ & & \\
\hline & & & & & $-0.0516^{*}$ & $\begin{array}{l}(0.0170) \\
0.0159 * *\end{array}$ & & \\
\hline & & & & & $(0.0273)$ & $(0.00619)$ & & \\
\hline \multirow[t]{2}{*}{ GUF P-R\&D pc } & & & & & & & -0.000704 & -0.00322 \\
\hline & & & & & & & $(0.0331)$ & $(0.0197)$ \\
\hline \multirow[t]{2}{*}{ No-GUF P-R\&D pc } & & & & & & & $-0.123 * *$ & -0.0260 \\
\hline & & & & & & & $(0.0596)$ & $(0.0160)$ \\
\hline Observations & 1,764 & 1,747 & 1,747 & 1,747 & 1,747 & 1,747 & 1,731 & 1,731 \\
\hline
\end{tabular}


Robust standard errors in parentheses $* * * \mathrm{p}<0.01, * * \mathrm{p}<0.05, * \mathrm{p}<0.1$ 


\section{REFERENCES}

Abreu, M., Grinevich, V., Kitson, M., and M. Savona (2008) Absorptive capacity and regional patterns of education. DIUS Research Report 08 11, Center for Business Research, University of Cambridge.

Akerlof, G. A. (1997) Social distance and social decision. Econometrica, 65: 10051027.

Arbia, G., Battisti M. and G. Di Vaio (2010) Institutions and geography: Empirical test of spatial growth models for European regions, Economic Modelling, 27(1): 1221.

Basile R., Capello R. and A. Caragliu (2012) Technological interdependence and regional growth in Europe: Proximity and synergy in knowledge spillovers. Papers in Regional Science, 91 (4): 697-722.

Bathelt H., Malmberg A., and P. Maskell (2004) Clusters and knowledge: local buzz, global pipelines and the process of knowledge creation, Progress in Human Geography, 28 (1): 31-56.

Becattini, G., M. Bellandi and L. De Propris (2009) (eds.), A handbook of industrial districts. Cheltenham: Edward Elgar.

Benhabib, J., \& M. M. Spiegel (2005) Human capital and technology diffusion. In P. Aghion \& S. Durlauf (Eds.), Handbook of economic growth. North-Hollan: Elsevier.

Beugelsdijk S., Smeets R. and R. Zwinkels (2008) The impact of horizontal and vertical FDI on host's country economic growth. International Business Review 17: 452-472.

Beugelsdijk S., Klasing M. and P. Milionis (2015) Regional TFP Dißerences in Europe and What We CanLearn from Them. (wwz.unibas.ch/fileadmin/wwz/redaktion/dekanat/BKM_Draft_Tables_Ver2_4_Klasi ng_et_al.pdf)

Balland P.A. and D. Rigby (2015) The geography and evolution of complex knowledge, Papers in Evolutionary Economic Geography 15-02.

Boschma R. and S. Iammarino (2009) Related variety, trade linkages, and regional growth in Italy. Economic Geography 85:289-311.

Boschma, R. (2005) Proximity and innovation: a critical assessment. Regional Studies 39: 61-74.

Bottazzi L. and G. Peri (2002) Innovation and Spillovers in Regions: Evidence from European Patent Data. IGIER Working Paper Series No. 215.

Breschi, S. and F. Lissoni, (2001) Knowledge Spillovers and Local Innovation Systems: A Critical Survey. Industrial and Corporate Change, 10(4): 975-1005. 
Breschi, S. and F. Lissoni (2009) Mobility of skilled workers and co-invention networks: an anatomy of localized knowledge flows. Journal of Economic Geography, 9 (4): 439-468.

Camagni R. (1991) "Local milieu, uncertainty and innovation networks: towards a dynamic theory of economic space", in R. Camagni (ed.), Innovation networks: spatial perspectives, Belhaven-Pinter, London, 121-144 .

Capello R. (2009) Spatial Spillovers and Regional Growth. European Planning Studies, 17(5): 639-658.

Capello, R. (2009) Indivisibilities, Synergy And Proximity: The Need For An Integrated Approach To Agglomeration Economies. Tijdschrift voor Economische en Sociale Geografie, 100 (2): 145-159.

Capello, R. and C. Lenzi (2015) Knowledge, innovation and productivity gains across European regions. Regional Studies 49: 1788-1804.

Caragliu A. and P. Nijkamp (2008) The impact of regional absorptive capacity on spatial knowledge spillovers. Tinbergen Institute Discussion Papers 08-119/3, Tinbergen Institute.

Caragliu A. and P. Nijkamp (2015) Space and knowledge spillovers in European regions: the impact of different forms of proximity on spatial knowledge diffusion. Journal of Economic Geography, online first. DOI: 10.1093/jeg/lbv042.

Coe D. and E. Helpman (1995) International R\&D spillovers. European Economic Review, 39: 859-887.

Coe D., Helpman, E. and A. Hoffmaister (2009) International R\&D spillovers and institutions. European Economic Review, 53 (7): 723-741.

Cohen, W. M. and D. A. Levinthal (1990) Absorptive Capacity: A New Perspective on Learning and Innovation. Administrative Science Quarterly 35(1): 128-152.

Conley T.G. and E. Ligon (2002) Economic distance and cross-country spillovers. Journal of Economic Growth 7: 157-187.

Cortinovis N., and F. Van Oort (2015) Variety, Economic Growth and KnowledgeIntensity of European Regions: A Spatial Panel Analysis, Annals of Regional Science 55: 7-32.

Cipollina M., Giovannetti G., Pietrovito F. and Pozzolo A. (2012) FDI and Growth: What Cross-country Industry Data Say. The World Economy 35(11): 1599-1629.

Crescenzi R. and Rodríguez-Pose A. (2011) Innovation and regional growth in the European Union . Springer, Berlin, Germany.

Crescenzi R., Nathan M. and Rodríguez-Pose A. (2016) Do inventors talk to strangers? On proximity and collaborative knowledge creation. Research Policy, 45 (1): 177-194. 
Crespo, N., Fontoura, M.P. (2007) Determinant factors of FDI spillovers-what do we really know? World Development 35 (3), 410-425.

Desdoigts A. (1999) Patterns of economic development and the formation of clubs. Journal of Economic Growth 4: 305-330.

Durlauf SN, Kourtellos A, Minkin A. (2001) The local Solow growth model. European Economic Review 45: 928-940.

Gorodnichenko Y., SvejnarJ. and Terrell K. (2014) When does FDI have positive spillovers? Evidence from 17 transition market economies. Journal of Comparative Economics 42(4): 954-969.

Dall'Erba S. and Le Gallo J. (2008) Regional convergence and the impact of European Structural Funds over 1989-1999: a spatial econometric analysis, Papers in Regional Science, 87 (2), pp. 219-242.

Elhorst J.P. (2014) Spatial Econometrics: From Cross-sectional Data to Spatial Panels. Springer: Berlin New York Dordrecht London.

Ertur, C. and W. Koch (2007), Growth, technological interdependencies and spatial externalities: theory and evidence. Journal of Applied Econometrics 22: 1033-1062.

Ertur, C. and W. Koch (2011), A contribution to the theory and empirics of Schumpetrian growth with worldwide interactions. Journal of Economic Growth 16: 215-255.

Ertur C, Le Gallo J, Baumont C. (2006), The European regional convergence process, 1980-1995: do spatial regimes and spatial dependence matter? International Regional Science Review 29: 3-34.

Fagerberg J. (1988) International competitiveness. Economic Journal, 98(391): 355374.

Fracasso A. and Vittucci Marzetti G. (2015) International trade and R\&D spillovers, Journal of International Economics,96(1): 138-149

Frenken K., Van Oort F. and Verburg T. (2007) Related variety, unrelated variety and regional economic growth. Regional Studies 41:685-697.

Frenken, K., J. Hoekman \& F. van Oort (2007), Towards a European Research Area. Rotterdam: Nai Uitgevers \& Ruimtelijk Planbureau.

Fu X., Pietrobelli C., Soete L., 2011. The Role of Foreign Technology and Indigenous Innovation in the Emerging Economies: Technological Change and Catching-up, World Development 39, Issue 7, pp.1204-12.

Glaeser E et al. (1992) Growth in cities. The Journal of Political Economy 100:11261152

Granovetter M. (1973) The strength of weak ties. American Journal of Sociology, 78(6):1360-1380. 
Greunz L. (2003) Geographically and technologically mediated knowledge spillovers between European regions. Annals of Regional Science, 37:657-680

Grossman, G. M., \& Helpman, E. (1991). Innovation and growth in the global economy. Cambridge, MA: MIT Press.

Grossman G. and Helpman E. (1994) Endogenous innovation in the theory of growth. The Journal of Economic Perspectives, 8 (1), pp. 23-44.

Hazir C.S., LeSage J.P. and Autant-Bernard C. (2014) The Role of R\&D Collaboration Networks on Regional Innovation Performance. Available at SSRN: http://ssrn.com/abstract=2507284 or http://dx.doi.org/10.2139/ssrn.2507284

Hausmann R., Hwang J. and Rodrik D. (2007) What you export matters. Journal of Economic Growth, 12 (1): 1:25.

Henderson J.V. (2003) Marshall's scale economies. Journal of Urban Economics 43: $1-28$.

Hidalgo C., Klinger, B., Barabási A.-L. and Hausmann R., (2007) The product space conditions the development of nations. Science, 317(5837): 482-487.

Hoekman J., Frenken, K., and van Oort, F.G. (2009) The geography of collaborative knowledge production in Europe. The annals of regional science, 43 (3), (pp. 721738)

Huggins R. and Thompson P. (2014) A network-based view of regional growth. Journal of Economic Geography 14(3): 511-545.

Huggins R., Johnston A. and Thompson P. (2012) Network capital, social capital and knowledge flow: how the nature of inter-organizational networks impacts on innovation. Industry and Innovation 19(3): 203-232.

Iammarino S. and McCann P. (2013) Multinationals and economic geography: location and technology, innovation. Edward Elgar, Cheltenham, UK.

Jacobs J (1969) The economy of cities. Random House, New York

Jaffe, A., Trajtenberg M. and Henderson R. (1993) Geographic Localization of Knowledge Spillovers as Evidenced by Patent Citations. The Quarterly Journal of Economics 108 (3): 577-598.

Jones C.I. (1995) R\&D-based models of economic growth. Journal of Political Economy 103: 759-784.

Keller, W. (2002) Geographic localization of international technology diffusion. American Economic Review, 92, 120-142.

Kirk, D. (1946) Europe's population in the interwar years. League of Nations, Geneva.

Knoben, K, A. Andac, F. van Oort \& O. Raspe (2016) Agglomeration and firm performance: one firm's medicine is another firm's poison. Environment \& Planning A 48: 132-153 
Lissoni F. (2016) Migration and Innovation Diffusion: An Eclectic Survey. Cahier $d u$ GREThA 2016-11, Université de Bordeaux.

Lissoni F. and Miguelez E. (2014) Patents, innovation and economic geography. Chaiers du GREThA 2014-16, Groupe de Recherche en Economie Théorique et Appliquée.

LeSage J. P. and Pace R. K. (2009) Introduction to Spatial Econometrics, Boca Raton, Taylor \& Francis.

Lucas R. (1988) On the mechanics of economic development. Journal of Monetary Economics 22: 3-42.

Lumenga-Neso O., Olarreaga M. and Schiff M. (2005) On 'indirect' trade-related R\&D spillovers. European Economic Review, 49 (7):1785-1798.

Maggioni M., Nosvelli M. and Uberti E. (2007) Space versus networks in the geography of innovation: A European analysis. Papers in Regional Science, 86: 471493.

Maggioni M. and Uberti E. (2009) Knowledge networks across Europe: which distance matters? Annals of Regional Science 43(3):691-720.

Mancusi M.L. (2008) International spillovers and absorptive capacity: A crosscountry cross-sector analysis based on patents and citations. Journal of International Economics 76(2):155-165.

Marshall A. (1920) Principles of economics: an introductory. Macmillan, London

Massard, N. and C. Autant-Bernard (2015) Geography of innovation: new trends and implications for public policy renewal. Regional Studies 49: 1767-1771.

Moreno R., Paci R., and S. Usai (2005) Spatial spillovers and innovation activity in European regions. Environmental Planning, 37:1793-1812.

Morgan, K. (1997) The learning region: institutions, innovation and regional renewal. Regional Studies 31: 491-503.

Morrison A., R. Rabellotti (2009), Knowledge and information networks in an Italian wine cluster, European and Planning Studies 17(7): 983-1006.

Morrison A., Rabellotti, R. \& L. Zirulia, (2013) When do global pipelines enhance the diffusion of knowledge in clusters?. Economic geography, 89 (1): pp. 77-96.

Nelson, R. R., \& E. S. Phelps, (1966) Investment in humans, technological diffusion, and economic growth. American Economic Review, 56(2), 69-75.

Nooteboom, B. (1992) Towards a dynamic theory of transactions, Journal of Evolutionary Economics, 2 (4): 281-299.

Ozman M. (2009) Inter-firm networks and innovation: a survey of literature. Economics of Innovation and New Technology 18:39 - 67.

Paci R., Marrocu E. and Usai S. (2014) The Complementary Effects of Proximity Dimensions on Knowledge Spillovers, Spatial Economic Analysis, 9(1): 9-30. 
Ponds, R., F. van Oort \& K. Frenken (2007) The geographical and institutional proximity of research collaboration. Papers in Regional Science 86: 423-444.

Ponds, R., F. van Oort \& K. Frenken (2010) Innovation, spillovers, and universityindustry collaboration: an extended knowledge production function approach, Journal of Economic Geography 10: 231-255.

Quah, D. (1996) Regional convergence clusters across Europe. European Economic Review, 40, 951-958.

Ratti, R., A. Bramanti and G. Richard (1997) (eds.) The dynamics of innovative regions. The GREMI approach. Alderhot; Ashgate.

Romer, P. M. (1986) Increasing Returns and Long-Run Growth. Journal of Political Economy, Vol. 94 (5): 1002-37.

Scherngell, T. (2013) The geography of networks and $R \& D$ collaborations. Berlin: Springer.

Thissen, M., D. Diodato \& F. van Oort (2013a) Integrated regional Europe: European regional trade flows in 2000. The Hague: Netherlands Environmental Assessment Agency (PBL).

Thissen, M., D. Diodato \& F. van Oort (2013b) Integration and convergence in regional Europe: European regional trade flows from 2000 to 2010. The Hague: Netherlands Environmental Assessment Agency (PBL).

Thissen M., T. de Graaff and F. van Oort (2016) Competitive network positions in trade and structural economic growth: A geographically weighted regression analysis for European regions. Papers in Regional Science 95(1): 159-180.

Todaro, M. P., \& Smith, S. C. (2009) Economic development. Pearson Addison Wesley, Boston.

Torre, A. and Gilly, J.P. (1999) On the analytical dimension of proximity dynamics, Regional Studies, 34 (2): 169-180. 